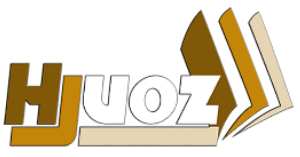

hjuoz.uoz.edu.krd p-ISSN: 2410-7557 e-ISSN: 2518-5128
كَّوارا زانستيّن مروّايهتى يا زانكوَيا زاخوّ

مجلة العلوم الانسانية لجامعة زاخو

Humanities Journal of University of Zakho (HJUOZ)

Vol. 4, No. 2, pp. 406-424, September-2016

https://doi.org/10.26436/2016.4.2.223

المستخلص أشار هذا البحث إلى بيان دور أهم مرتكزات إدارة الجودة الشاملة والمتمثلة في التزام الادارة العليا، التدريب ومشاركة الأفراد

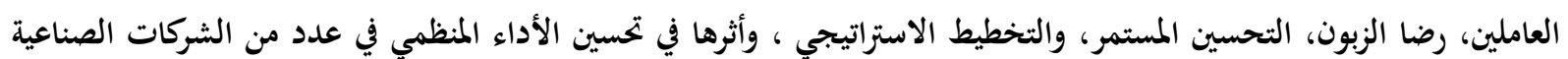

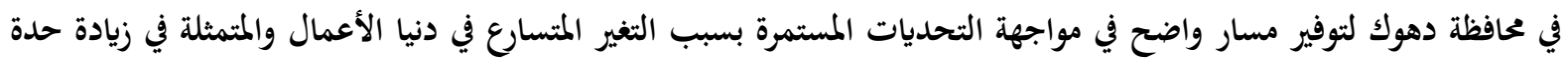

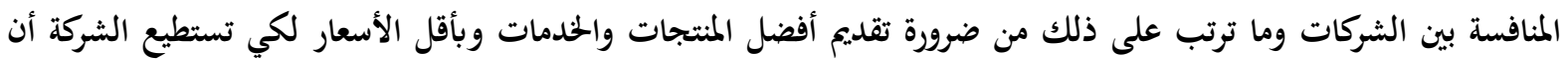
تثبت نفسها في هذا السوق التنافسي. وقد اختيرت مجموعة مكونة من ستة شركات صناعية لتكون مجالاً للتطبيق الميداني للبحث، واعتمد الباحث أسلوب الاستبانة

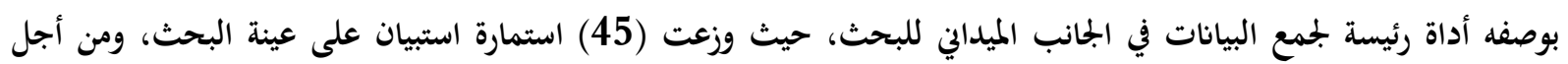

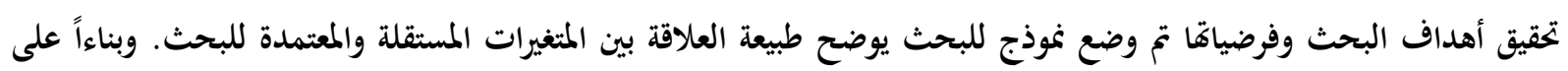

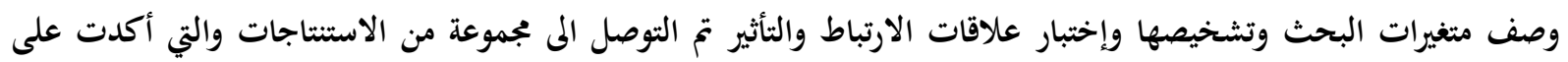

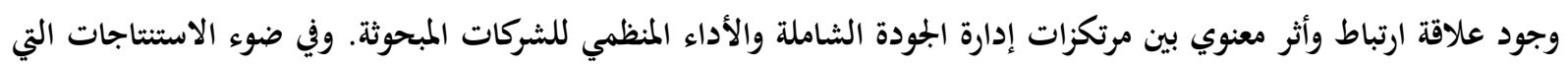

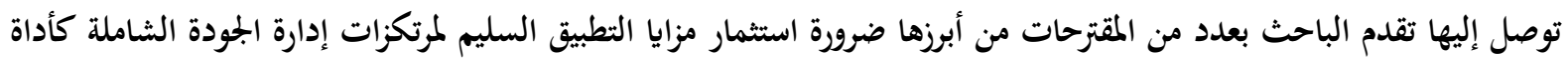
لتحقيق التحسين في الاداء المنظمي. الكلمات المفتاحية: متركزات إدارة الجودة الشاملة، الأداء المنظمي، تحسين الأداء، الأداء الوظيفي.

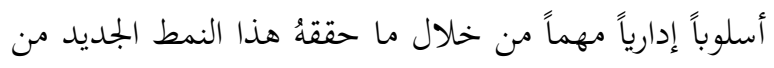

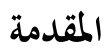

نجاحات ملموسة في الإدارة.

وكنتيجة لأهمية هذا المفهوم وانتشار تطبيقهِ في دول العارة. ازداد اهتمام الباحثين والدارسين ومراكز العلم به، وقدموا الكثير من المساهمات والمقترحات للشركات الصناعية والتي

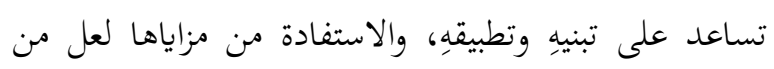
أهمها تحسين الأداء المنظمي والمتمثلة بتطوير منتجاتا القائمة

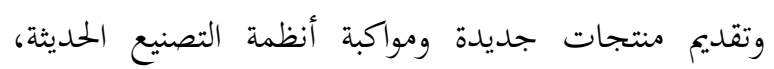
والوصول الى رضى زبائنها، وبالتالي تحقيق ميزة تنافسية والقدرة

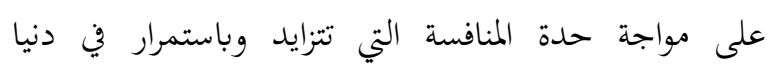

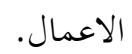

وقد تناول البحث في إطارها النظري مبحثين، تناول المبحث الأول إدارة الجودة الشاملة، بينما تناول المبحث
تعد إدارة الجودة الشاملة فلسفة إدارية عصرية ترتكز على عدد من المفاهيم الإدارية الحديثة الموجهة، التي تقوم على المزج

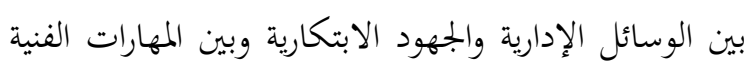

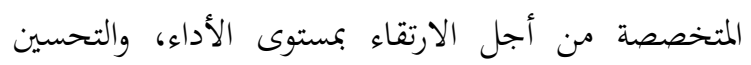
والتطوير المستمرين. وقد بدأت في تطبيقهِ العديد من الن رنساء المنظمات الإدارية لتحسين إنتاجها وتطوير نوعية خدماتمات ولمدات

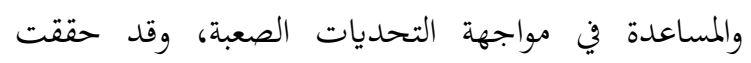

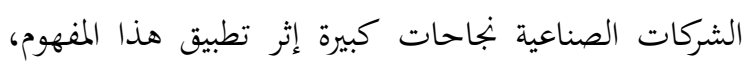

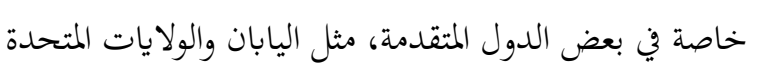
وفرنسا وبريطانيا. لذلك أصبح مفهوم إدارة الجودة الشاملة 
يهدف البحث الم محاولة إدخال التحسين المستمر للاداء

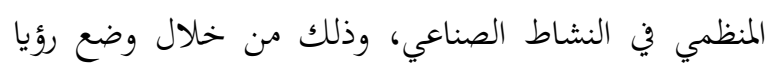

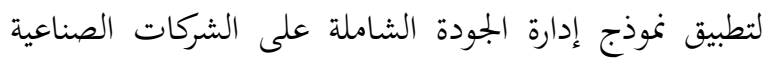

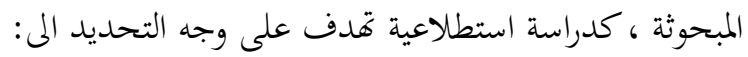

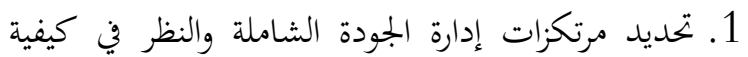
تطبيقها داخل الشركات الصناعية.

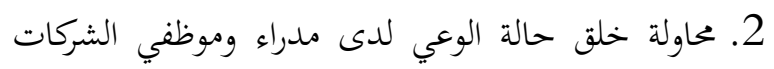

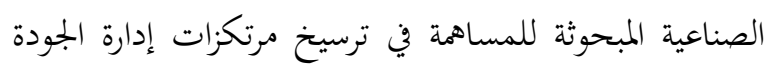
الشاملة في الشركة. ومحاولة تطبيق نموذجها الذي يفسر لئهر المتغيرات المختلفة والمتعلقة بمدى استعداد الشركات الصناعية المبحوثة لتطبيق إدارة الجودة الشاملة.

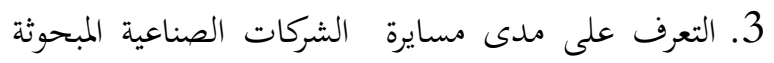
للمناهج العلمية المتعلقة بادارة الجودة الشاملة، والإداء المنظمي. 4. محاولة لتحديد أبرز العقبات التي تواجة تطبيق ادارة الجودة الشاملة في الشركات الصناعية المبحوثة. 5. تحديد أثر مرتكزات إدارة الجودة الشاملة في تحسين الأداء المنظمي في الشركات الصناعية المبحوثة.

\section{فرضيات البحث}

لغرض استكمال متطلبات البحث في إطاره العملي وفي ضوء مشكلة البحث وأهدافهِ واختبار طبيعة العلاقة القائمة بين المتغيرات الرئيسة والفرعية يتطلب صياغة وإختبار فرضية

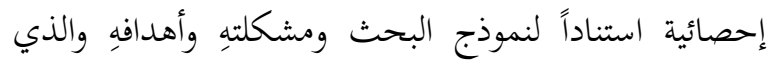

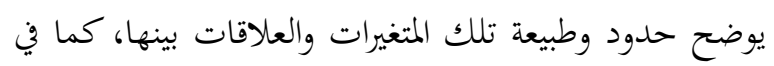

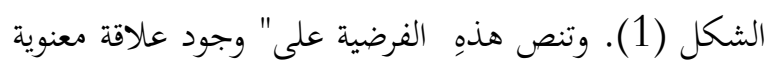

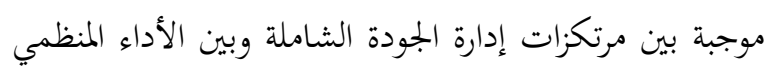

$$
\text { في الشركات المبحوثة". }
$$
تتطلب المعالجة المنهجية لمشكلة البحث في ضوء اطارها النظري ومضامينهِ الميدانية تصميم نموذج للبحث كما فيه الشكل (1) والذي يشير الى علاقات الارتباط والتاثير بين
الثاني، الأداء المنظمي، بينما تناول الجانب الميداني للبحث تحديد أثر مرتكزات إدارة الججودة الشاملة في تحسين الأداء المنظمي، وبالتطبيق على عدد من الشركات الصناعية في

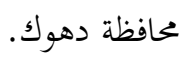

\section{منهجية البحث} مشكلة البحث منجه البحث

لا تزال أهمية إدارة الجودة الشاملة غير واضحة لدى الكثير

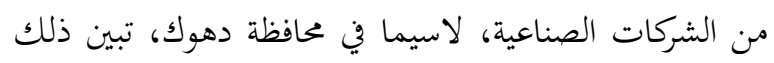
من خلال الزيارات الميدانية لواقع حال عدد من هذهِ الشركات، حيث اها تعاني من مشكلة تدني مستوى جودة منتجاها مقارنةً بالمنتجات المستوردة، إضافةً المى عدم الإدراك

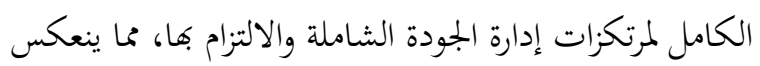
سلباً على ضعف الأداء المنظمي، خاصةً واها تعمل في بيئة تنافسية، وسريعة التغيير.

أهمية البحث تعد الجودة سلاحاً تنافسياً تعتمدهُ معظم الشركات

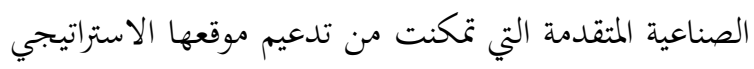

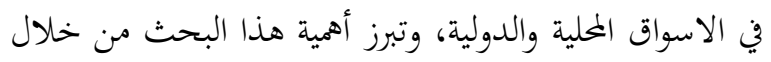

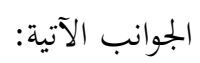
1. تتناول موضوعاً غاية في الأهمية، ألا وهو تطبيق مرتكزات إدارة الجودة الشاملة في الشركات الصناعية من حيث تسليط الضوء على (التزام الادارة العليا، التدريب ومشاركة الأفراد

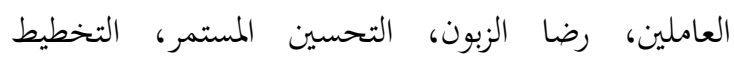
الاستراتيجي). 2. الارتقاء بالعمل الإداري في الشركات الصناعية في ضوء

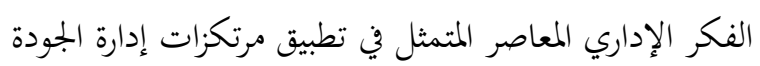
الشاملة. 3. بناء ثقافة في الشركات الصناعية لدعم عملية تطبيق

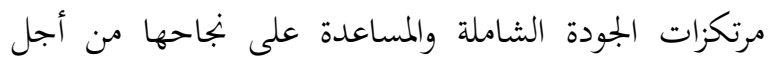
تحسين الاداء المنظمي. أهداف البحث 


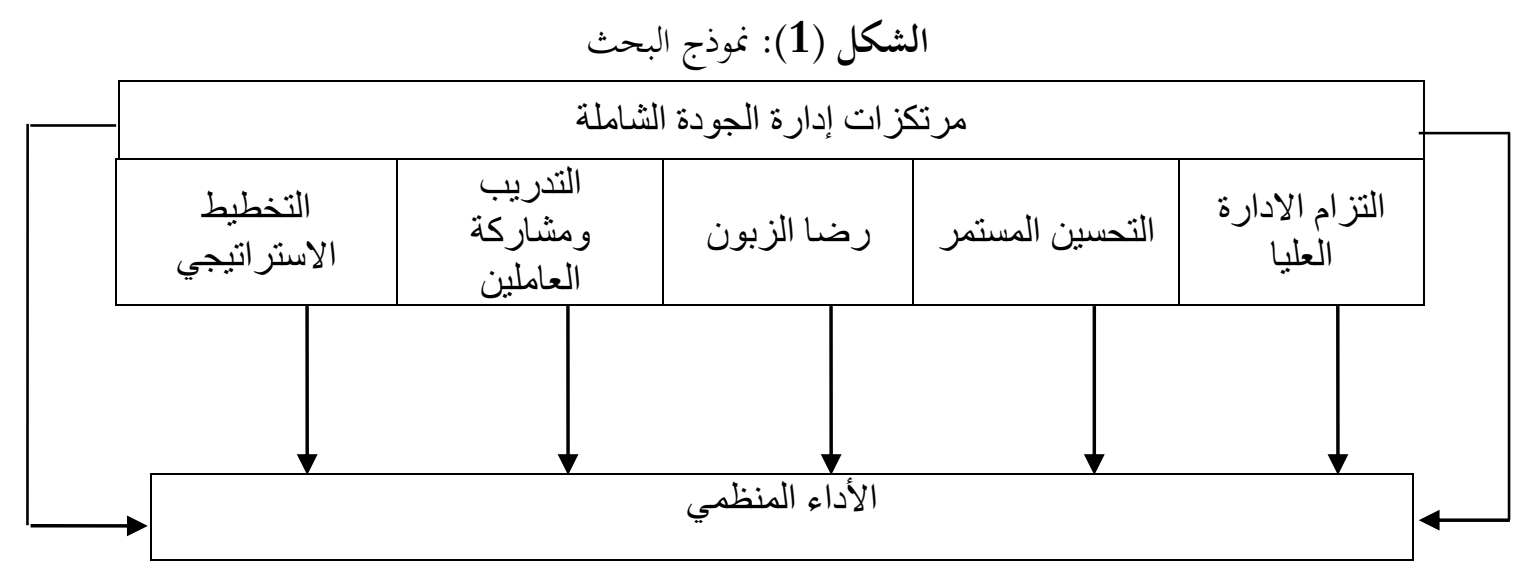

خدمة بأعلى جوده ممكنة، وإيجاد مزايا تنافسية استجابة للتغيرات الاقتصادية والإدارية المتلاحقة والتطورات المتواكبة في ماني

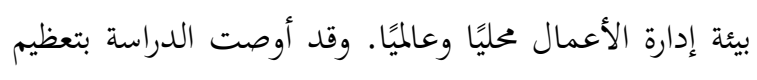

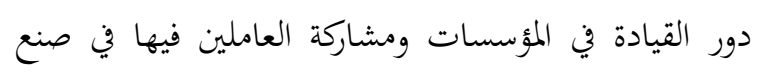

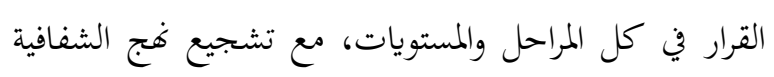

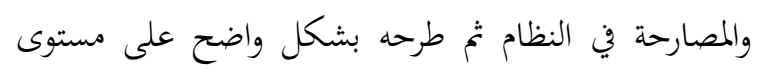

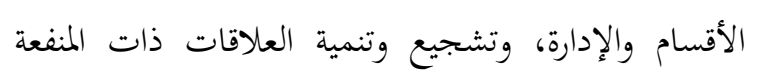

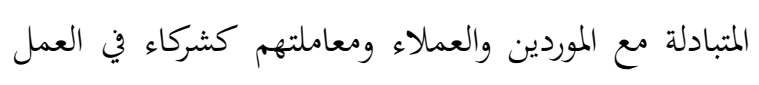
والإنتاج.

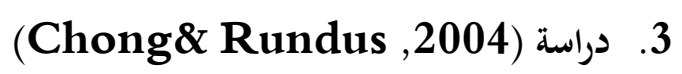
الدراسة بعنوان" إدارة الجودة الشاملة والمنافسة السوقية والأداء التنظيمي"، وقد هدفت تلك الدراسة إلى إختبار تأثير

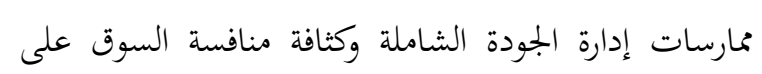
الأداء التنظيمي، ذلك من خلال إختبار العلاقة بين التركيز

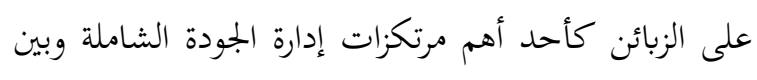
الأداء التنظيمي، وأيضا من خلال إختبار العلاقة بين التركيز

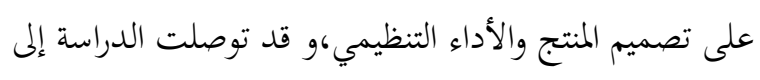
أنه هناك علاقة ذات دلالة معنوية بين منافسة السوق والتركيز على الزبائن والأداء التنظيمي، كما توصلت إلى أنه كلما زادت منافسة السوق زادت العلاقة بين الأداء التنظيمي

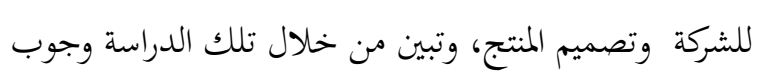

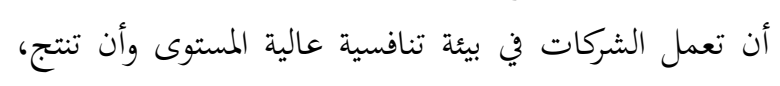

الدراسات السابقة 1. دراسة (الطويل وسلطان ، 2001: 11-29) عنوان الدراسة (إمكانية تطبيق إدارة الجودة الشاملة في الصناعات العراقية - دراسة استطلاعية لأراء المدراء في عينة

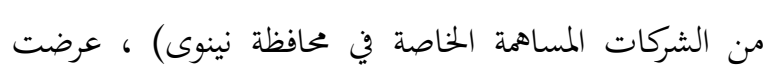

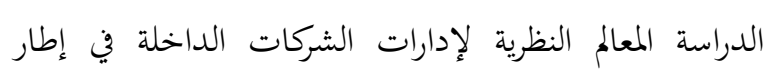

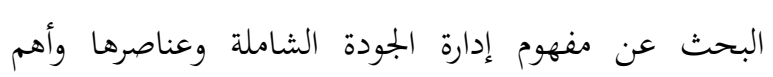

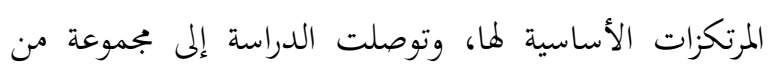

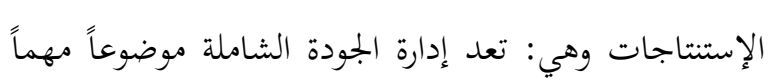

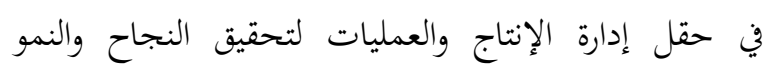

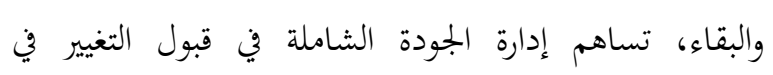
المنظمات المنافسة بوصفها واقعاً ضرورياً وبيان أهمية الزبائن

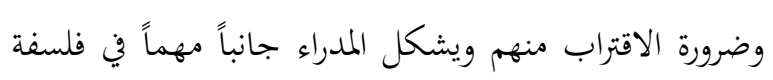
إدارة الجودة الشاملة من خلال تعرفهم على منى مفاهيم ومستلزمات هذه الفلسفة وتوجيه أفراد المنظمة لتقبلها .

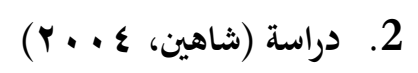

الدراسة بعنوان" إدارة الجودة الشاملة وأنظمتها في نجاح المنظمة والمنتج"، وقد هدفت تلك الدراسة إلى التعرف على إده إنه

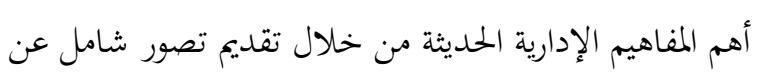

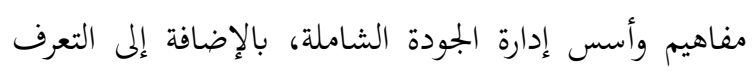

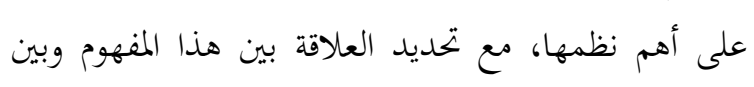
الأنظمة المساندة له؛ بغرض رفع مستوى أداء المنظمة والأفراد

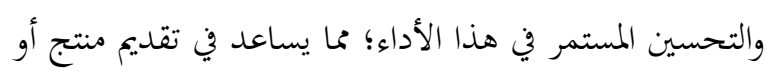


أما ما يتعلق بمفهوم إدارة الجودة الشاملة فسوف نستعرض

$$
\text { آراء عدد من الباحثين وكالآتي: }
$$

1. إدارة الجودة الشاملة هي تأكيد الجودة الذي تشمل جميع أجزاء وعمليات المنظمة، التي تبدأ من مرحلة التعامل مع المجهزين إلى تسليم السلع أو الخدمة إلى الزبون. .(Heizer\&Render, 2001:175) 2. إدارة الجودة الشاملة فلسفة إدارية موجهة على أساس التحسين المستمر والاستجابة لإحتياجات الزبون وتوقعاتهِ. .(Robbins \& Coulter, 2005: 63) 3. إدارة الجودة الشاملة هي نظام إداري يقوم على عددٍ من الأُسس والمتطلبات المتمثلة في الوعي بفلسفة ومفهوم الجودة إنها الشاملة، واقتناع والتزام القيادة بتطبيقها، وذلك من خلال القيام بعمليات المشاركة والتخطيط الاستراتيجي والتركيز على العملاء الداخليين والخارجيين، والتحسين المستمر للأداء والخدمات والمنتجات المقدمة، وتحديد معايير القياس وتحليل المهام، ومنع الأخطاء قبل وقوعها، وتقديم التحفيز اللازم للعاملين، وتوفير التدريب المناسب. (السامرائي، 2012:

4. ادارة الجودة الشاملة هي نظام يستخدم بشكل أمثل جمموعة من الفلسفات الفكرية المتكاملة والعمليات التسييرية والادوات الاحصائية والموارد المالية والبشرية بهدف تلبية احتياجات العميل الداخلي (العامل داخل المؤسسة)، والخارجي (زبون المؤسسة ) على حد سواء. وهي نظام يلتزم بتقديم قيمة للعملاء من خلال إيجاد بيئة يتم فيها تحسين وتطوير مستمر لمهارات الأفراد ولنظم العمل، مع الالتزام بارضاء العميل ودعم العمل الجماعي، وبالتالي تحقيق أهداف المؤسسة الإستراتيجية و وإمتلاك ميزة تنافسية مستدامة. (مناصرية، 2012: 193). ثانياً/ أهداف إدارة الجودة الشاملة لإدارة الجودة الشاملة عدد من الأهداف التي ترغب إدارة المنظمة في تحقيقها، والتي يجب عليها معرفة كيفية إدارة هذِِ الأهداف في الإتجاه الصحيح وتنفيذها في الوقت المناسب، وعلى إدارة المنظمة الإهتمام بالموازنة بين أهداف إدارة الجودة
وتسوق منتجات ذات جودة عالية لمقابلة توقعات ورغبات الزبائن لتحقيق الجودة التنافسية.

\section{المبحث الاول: إدارة الجودة الثاملة

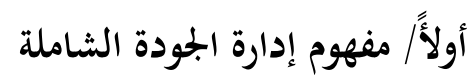

يعد مفهوم إدارة الجودة الشاملة من المفاهيم المعاصرة والمامة التي تسعى الشركات والمنظمات كافة في مختلف الدول الى تطبيقها من أجل الوصول الى أفضل أداء ممكن. ولقد ولد مفهوم الجودة وتحسينها بمعناه الحديث في اليابان، وذلك مع بداية العقد الخنامس من القرن العشرين. ثم انتشر بعد ذلك في شمال أمريكا ودول أوروبا الغربية، إلى أن أصبح موضوع العصر، حيث تجسد في فه إداري حديث، أطلق عليه تسمية إدارة الجودة الشاملة. فقام بتطوير مفهوم الإدارة القديم، ليتماشى مع التوجيهات الحديثة والمعاصرة، التي تؤكد على تحقيق الجودة العالية لكسب رضا العملاء. (عقيلي،

وقبل الخوض في إعطاء مفهوم عن إدارة الجودة الشاملة نبين أولاً مفهوم الجودة، حيث تعددت تعاريف الجودة باختلاف النظرة اليها وباختلاف وتطور مفهومها في حد ذاته، لذلك يعرفها (عبد الحميد ومراد، 2008: 4) على أفها مجموعة من المواصفات والخصائص التي تحددها المؤسسة، والتي يجب أن يتضمنها المنتوج أثناء عمليتي التصميم والتصنيع. أو أها انتاج المؤسسة لسلعة أو تقديم خدمة بمستوى عالٍ من الجودة المتميزة وتكون من خلالما قادرة على الوفاء باحتياجات ورغبات زبائنها، بالشكل الذي يتفق مع توقعاهم وتحقيق الرضا والسعادة لديهم، ويتم ذلك من خلال مقاييس موضوعة سلفاً لانتاج السلعة أو تقديم الخلدمة وإيجاد صفة التميز فيها. في حين اشار(Allen,2003:88) الى أن الجودة هي تلبية ما يتوقعهُ المستفيد أو ما تفوق توقعاتهِه، وأن الجودة هي الملائمة للاستعمال. 
1 والأسواق بما يمكنها من تلبية متطلبات الزبائن.

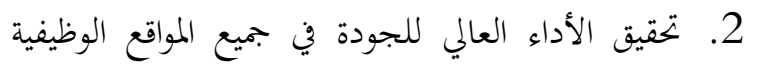
وعدم إقتصارها على السلع والخدمات.

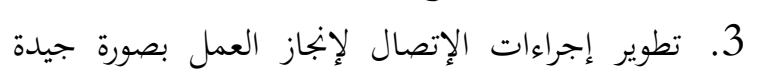

$$
\text { ومتميزة. }
$$

$$
\text { 4. ت ت تحسين سمعة الشركة. }
$$

5. تخفيض التكاليف وتحقيق مزايا تنافسية للشركة وتطويرها وبالتالي زيادة الحصة السوقية للشركة وأرباحها، محققةً البقاء

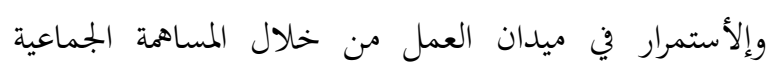

والتحسينات على جودة المدخلات والعمليات والمخرجات. 6. تنمية الشعور بوحدة المجموعة وعمل الفريق والثقة المتبادلة

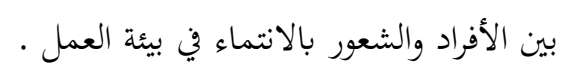

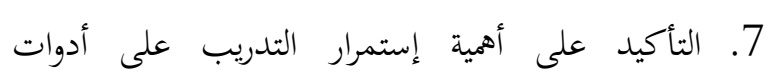

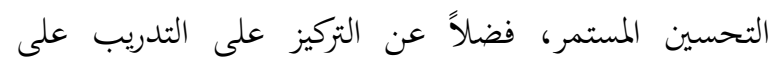

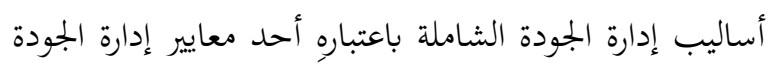

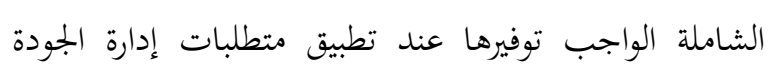
الشاملة . كما تنبع أهمية إدارة الجودة الشاملة من خلال المزايا التي

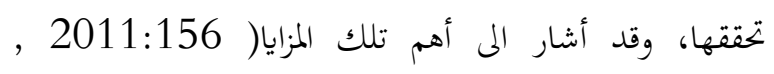

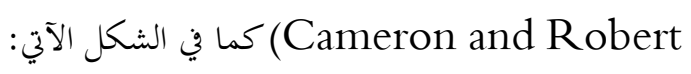

الشاملة وفق معيار الأهمية النسبية، والعمل على علاج أوجه الضعف في الشركة يتطلب تحقيق أهداف إدارة الجودة الشاملة،

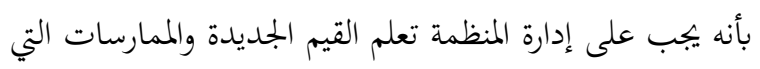

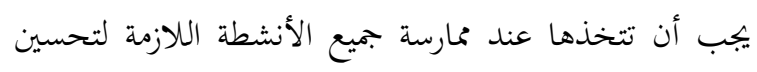

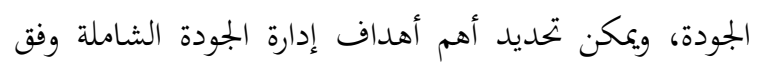
الآتي:(Dimitriades, 2001:33) 1. 1 إستقرار جودة المنتجات.

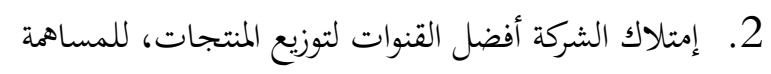

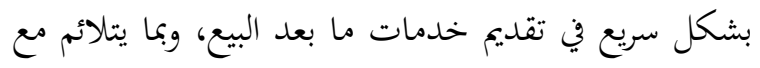
إحتياجات المستهلك. 3. تحقيق المرونة الدائمة والتكيف مع زيادة القدرة على إجراء

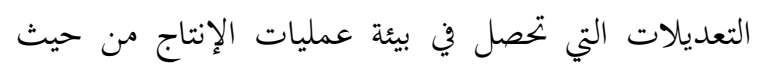
حجم ونوع المتطلبات، ووفقاً لإحتياجات المستهلك.

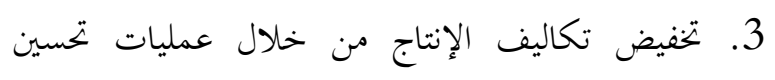
الجودة، وتقليل العيوب في العمليات أو المنتجات التامين الصنع. (1) 4. رضا الزبون من خلال تحقيق متطلباتِهِ لضمان البقاء والاستمرار. ثالثاً/ أهمية تطبيق الجودة الشاملة في الشركات الصناعية إن تطبيق الجودة الشاملة في الشركات الصناعية تحقق أهمية

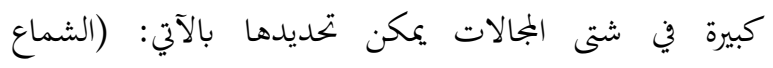
وآخرون، 2001: الشكل (2): مزايا تطبيق ادارة الجودة الشاملة 


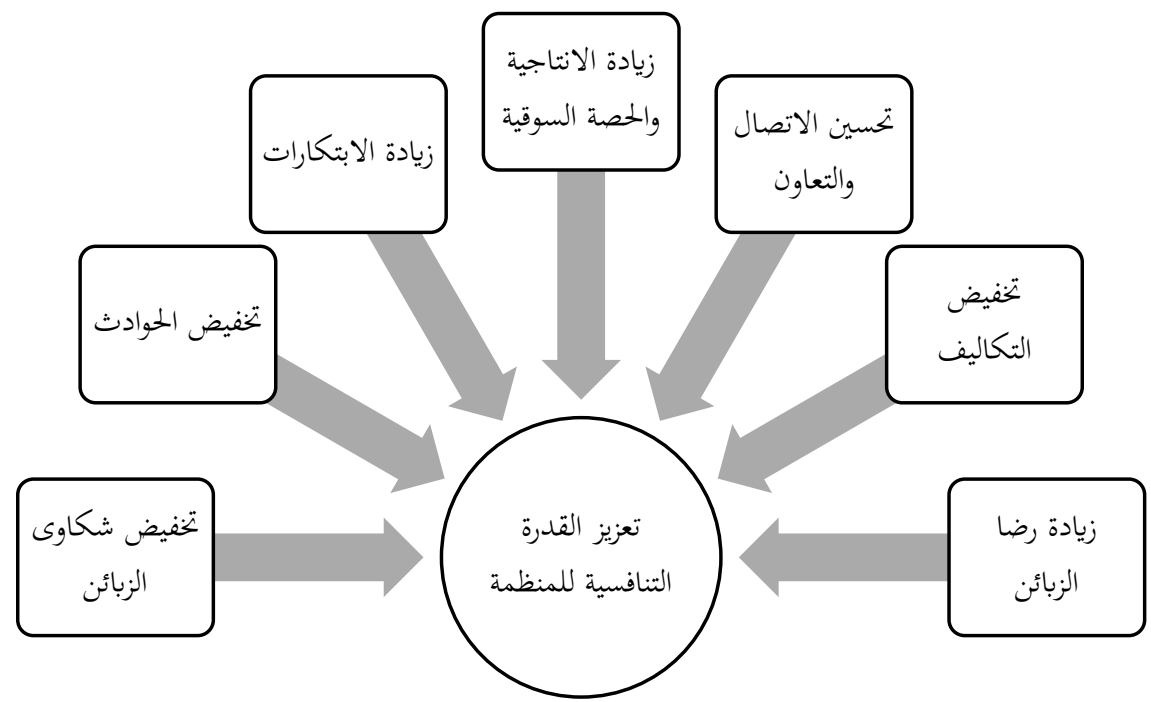

Robert: Diagnosing and Changing Organizational ،Quinn Cameron, Kim and المصدر: Culture: Based on the Competing Values Framework, John Wiley and Sons, 2011, P.156.

إنّ التنامي المستمر لحاجات ورغبات العملاء والأطراف الأخرى ذات المصلحة يفرض على المنظمات أن تحسن أداءها

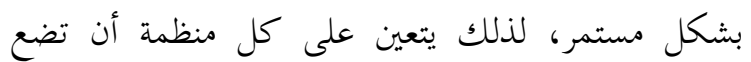

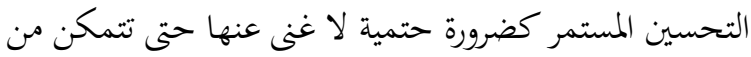
مجاراة التغيرات المحيطة بها، إنّ الحديث عن تحسين المنظمة لفعاليتها وكفاءتما يقودنا مباشرة إلى الحديث عن واحدة من المقاربات الإدارية الحديثة القائمة على هذا الأساس ونقصد بها

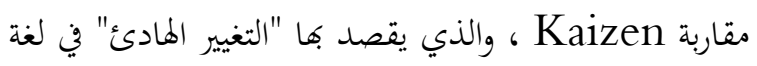
اليابان وهي الدولة آتّي ظهرت فيها. إلا أنّ المصطلح المتداول

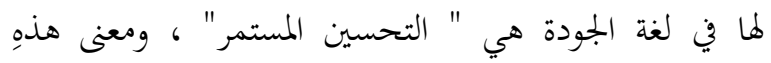
المقاربة أن على كل فرد في المنظمة، من المدير العام الى العامل البسيط، أن يساهم بثبات في تحسين نشاطات المنظمة،

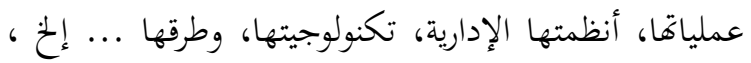

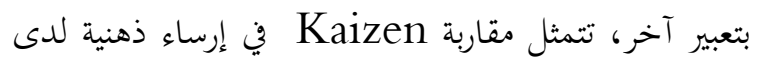

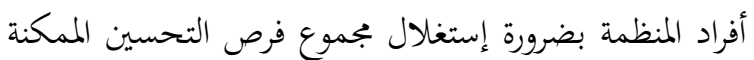

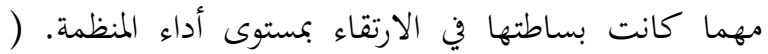

$$
\begin{aligned}
& \text { ملوك، 2010: 39). } \\
& \text { 3. رضا الزبون }
\end{aligned}
$$

\section{رابعاً مرتكزات إدارة الجودة الشاملة} يتضمن اسلوب إدارة الجودة الشاملة بجموعة من المرتكزات الواجب الإلتزام بها لتحقيق النجاح في تطبيق هذا المفهوم، والأهداف التي يسعى هذا الأسلوب الإداري الى تحقيقها والمتمثلة في تحسين الأداء المنظمي، وتتمثل هذهِ المرتكزات

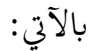

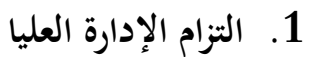
ويقصد بها ضرورة إهتمام الإدارة العليا بمبدأ تحسين إدارة الجودة، أي العمل على تحسين نوعية وجودة الخدمات المقدمة أو السلع المنتجة، وكذلك ضرورة إدراك الإدارة العليا والعاملين

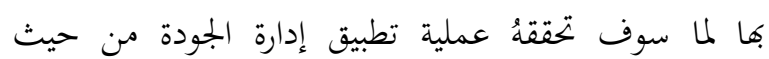

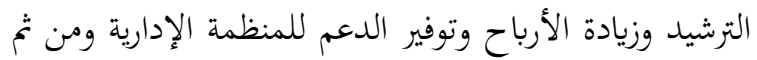
دعم الإدارة واستمرارية نجاحها. إن تبني الإدارة العليا وحماسها لمفهوم إدارة الجودة الشاملة ودعم تطبيق هذا المبدأ وتحديث وتطوير متطلبات التطبيق يعتبر حجر الأساس في نجاح المنظمة، ونجاح الأفراد، ونجاح تطبيق مفهوم إدارة الجودة

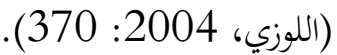
2. - التحسين المستمر 
تحسين مستوى الأداء للأفراد. وللتدريب دور مهم في نجاح

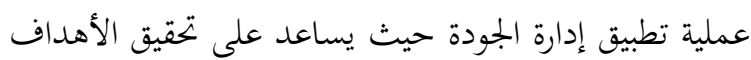
التالية :

أ- - تزويد الأفراد بمعلومات متجددة عن طبيعة الأعمال والأساليب. ب- - إعطاء الأفراد الفرص الكافية لتطبيق هذهِ المعلومات والمهارات.

أما مشاركة العاملين فيقصد بها مشاركتهم في كل نشاط

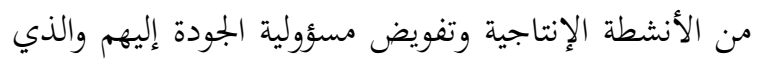

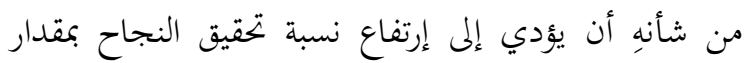

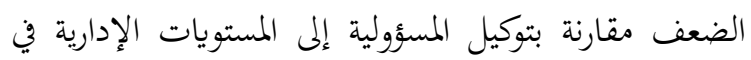
المنظمة (الصفار وعبد اللطيف، 2008: 10). ومن وجهة إلمنة

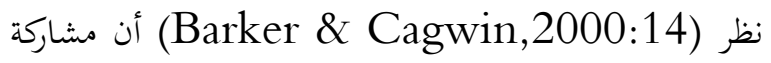
العاملين يقصد بها "إعطاء العمال التدريب والسلطة التي يحتاجون إليها لمساعدقم على أداء وظائفهم بشكل جيد " . . ويوضح (Evans , 1997: 97) إن مشاركة العاملين يكون من خلال تحملهم المسؤولية الكاملة نهو تحسين جودة منتجات المنظمة، فهم يحتاجون دائما إلى دورات تدريبية

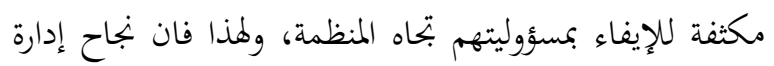

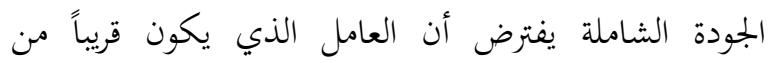

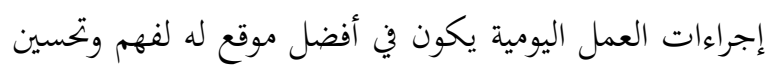
جودة هذهِ الإجراءات. 5. التخطيط الاستراتيجي

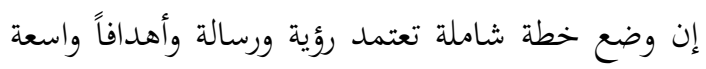

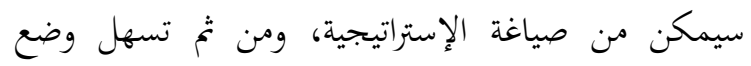
السياسات والبرامج في ضوء تحليل معمق للبيئة الداخلية والخارجية باعتماد تحليل نقاط القوة والضعف في البيئة

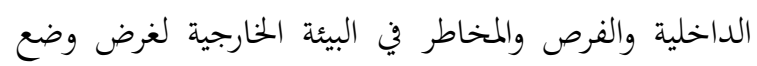
الخطط الشاملة بالشكل الذي يوفر قابلية دعم للميزة التنافسية للمنظمة، فالتخطيط الإستراتيجي هو تفكير إستراتيجي منظم

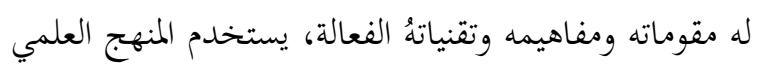
لإستشراف متغيرات المستقبل وتحليل بيئة المنظمة داخلياً وخارجياً للإستفادة من الفرص المتاحة ومواجهة التحديات
يؤكد (Slack, et. al, 2004: 719) إن منهج إدارة الجودة الشاملة تعني تلبية توقعات الزبائن، ورؤية الأشياء

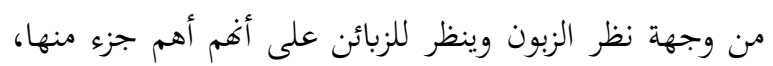

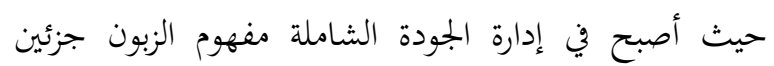

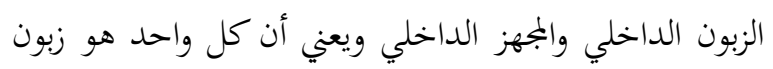
داخل المنظمة ويستهلك المنتجات المقدمة من قبل المجهزين

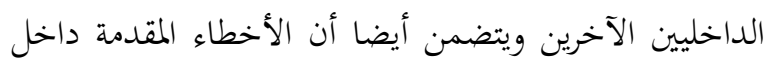

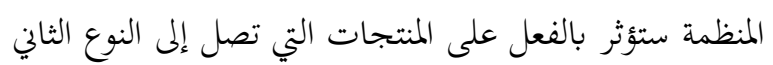

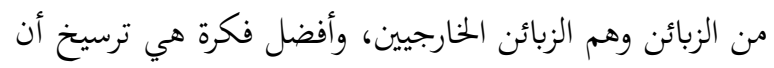

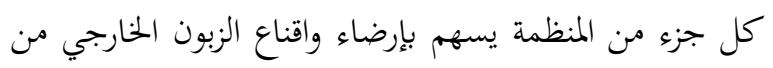

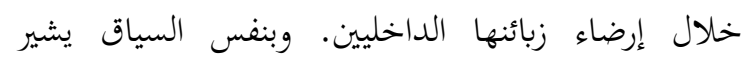
(Besterfield et.al: 2005)

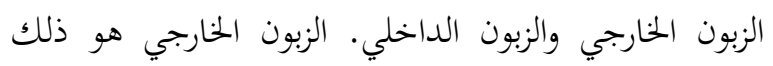

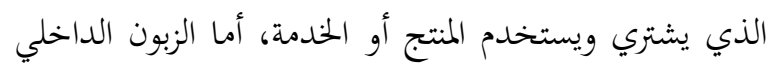

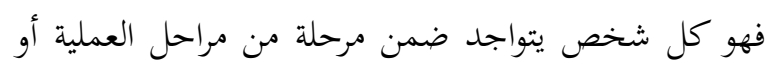

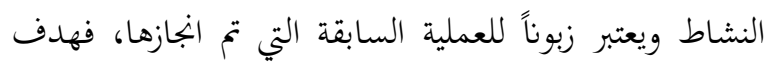
كل موظف في هذا الشان هو التاكد من أن الجودة تفي الجناني بتوقعات الشخص الذي يلي. (Steven \& Wynne , 2004 : 527) و (Thomas \& Lawrence, 2004: 399) إن الرضا والاحتفاظ بالزبون يكون من خلال الخدمات النموذجية

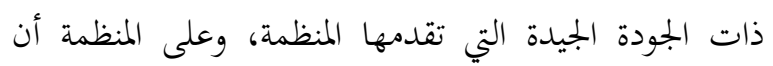

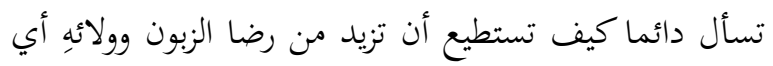
بمعنى آخر كيف تربح الزبون، لأن رضا الزبون يقود إلى دئل

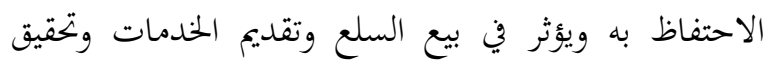
الأرباح. 4. التدريب ومشاركة الأفراد العاملين يشير (اللوزي، 2004: 371) الى أن نجاح إدارة الجودة

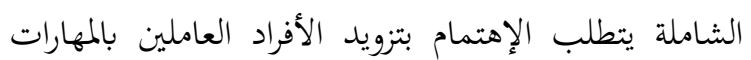

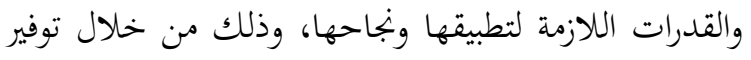
برامج تدريبية مؤهلة قادرة على إيصال المعلومات والمهارات

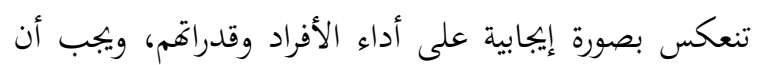

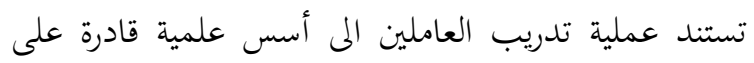


3. الأهمية الإدارية: تظهر من خلال حجم الاهتمام الكبير

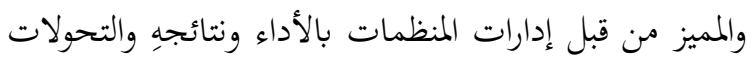
التي تجري في هذهِ المنظمات إعتماداً على نتائج الأداء. ثالثاً/ تصنيف الأداء المنظمي توجد عدة تصنيفات للأداء ولعل هذا يرجع الى الاختلاف في إبحاهات الباحثين، ويمكن تصنيف الأداء

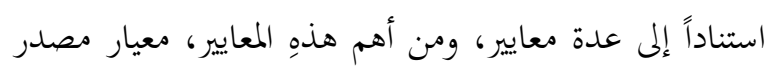
الأداء، ومعيار الشمولية، والمعيار الوظيفي، وكالآتي: 1 / معيار مصدر الأداء وفقا لهذا المعيار يمكن تقسيم أداء المنظمة إلى أداء داخلي

وأداء خارجي: (سليماني، 2007: 118. 119) أ. الأداء الداخلي: وينتج من تفاعل مختلف أداء الأنظمة

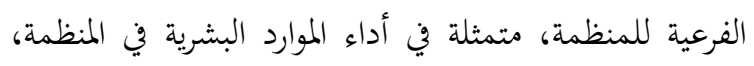
والأداء التقني الذي يتعلق بجانب الاستثمارات، والأداء المالي الخاص بالإمكانيات المالية المستعملة. ب. الأداء الخارجي: وهو الأداء الناتج عن تغيرات البيئة

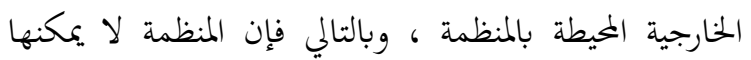
التحكم في هذا الأداء، حيث قد يظهر هذا الأداء في نتائج

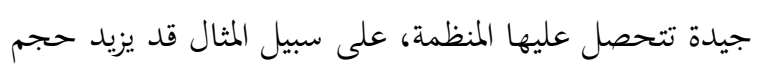

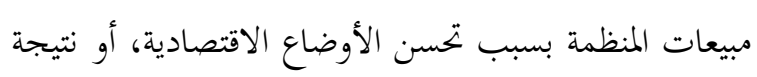

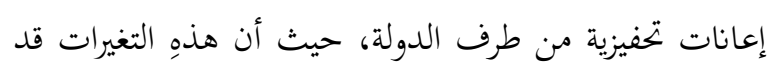

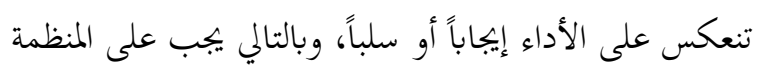

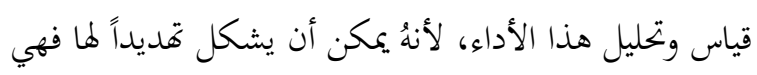
لا تتحكم فيه كما هو الحال بالنسبة للأداء الداخلي.

$$
\text { 2/ معيار الثمولية }
$$

يقسم الأداء المنظمي حسب هذا لمعيه المعيار إلى أداء كلي

وأداء جزئي، وكالآتي: (أم العز، 2012:

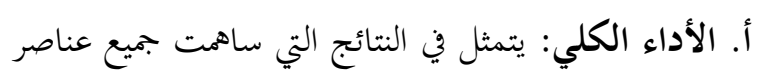

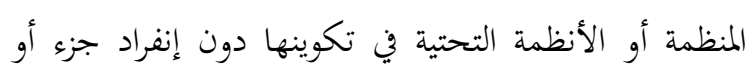

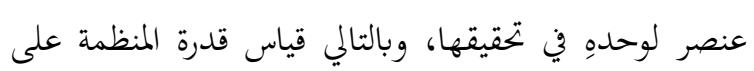

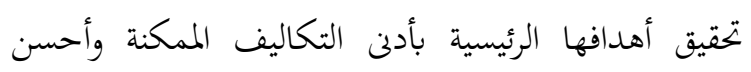
جودة.
القائمة والمتوقعة بصورة تمكن من بناء إستراتيجيات قابلة للتنفيذ مستمدة من البدائل والخيارات المطروحة بغية الوصول بناء

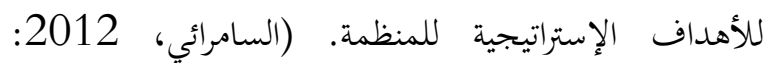

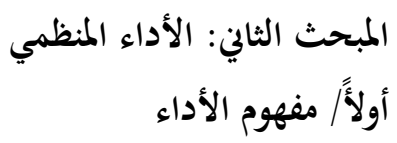

يستخدم مصطلح الأداء على نطاق واسع في ميدان

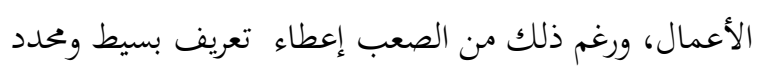
له، فالأداء هو الترجمة اللغوية للكلمة الانجليزي

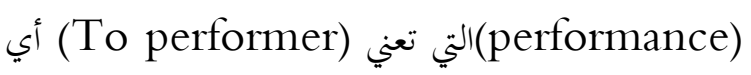
ننجز أو نؤدي عملاً، وبعد ترجمتها إلى اللغة الفرنسية منحت

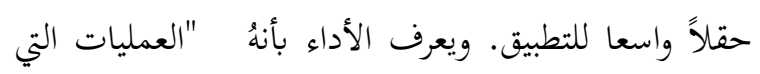

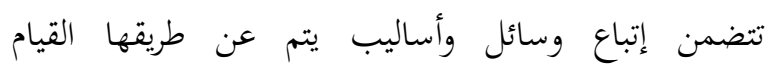
بالنشاطات للوصول إلى أهداف هذهِ النشاطات، باستخدام

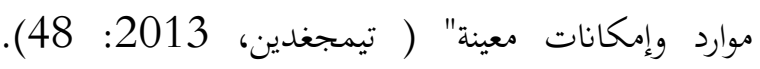
فالأداء يعبر عن قدرة المنظمة على تحقيق أهدافها الطويلة

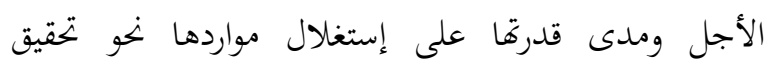
الأهداف المنشودة، فالأداء دالة لكافة أنشطة المنظمة وهو آلمات المرآة التي تعكس وضع المنظمة من مختلف جوانبها، وتسعى

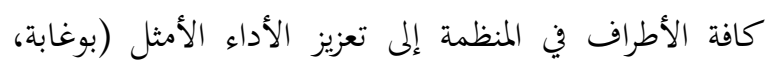

أما تحسين الاداء فهو الفعل الذي يقود الى إنجاز الأعمال

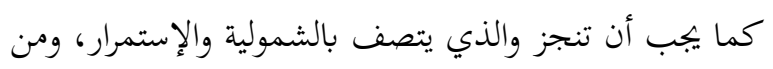

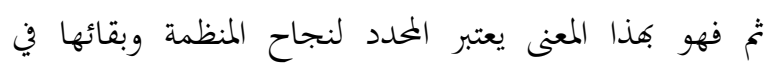

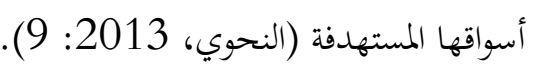
ثانياً/ أهمية الأداء يمكن مناقشة أهمية الأداء من خلال ثلاثة أبعاد رئيسية

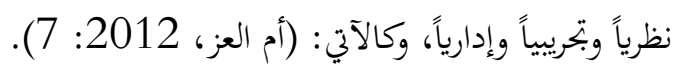
1.الناحية النظرية: يعتبر الأداء مركز الإدارة الإستراتيجية لأنه يمثل اختباراً زمنياً للإستراتيجية المتبعة من قبل الإدارة.

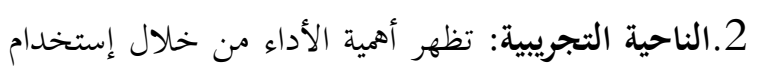
أغلب دراسات وبكوث الإدارة الإستراتيجية لإختبار

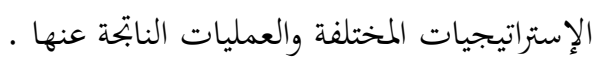


الأحيان الى خلافات كبيرة بين العمال تفسر غالباً بالنسبة

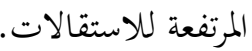

ح/ أداء وظيفة الأفراد (الموارد البشرية): وتعتبر وظيفة

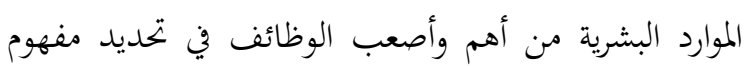

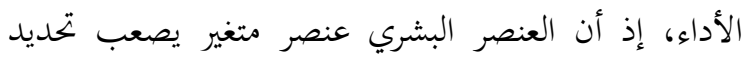

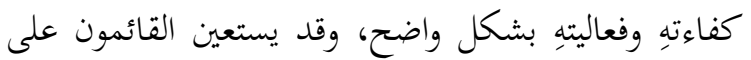

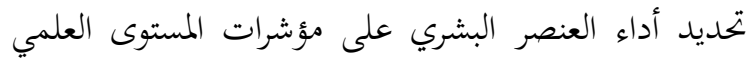

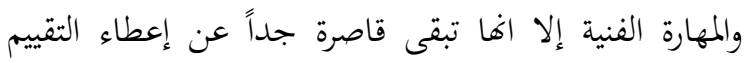

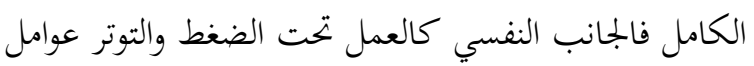
لا يمكن إخضاعها للدراسة أو الوصف الذي يمكن معه تحديد

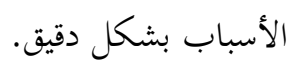

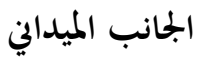

همدف بيان العلاقة والأثر بين مرتكزات إدارة الجودة

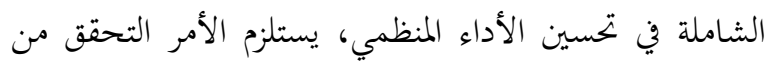
صحة الفرضيات والتي تؤكد على وجود علاقة إرتباط وتاثير معنوي بين مرتكزات إدارة الجودة الشاملة في تحسين الأداء المنظمي في الشركات المبحوثة، وقبل الدخول في تحديد العلاقة

والأثر بين متغيرات البحث، نقدم نبذة عن عينة البحث.

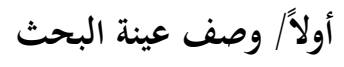

يعرض هذا المحور وصفاً لعينة البحث وكالآتي:

$$
\text { 1. وصف الشركات المبحوثة }
$$

تعد الشركات الصناعية بشكل عام إحدى الركائز المهمة

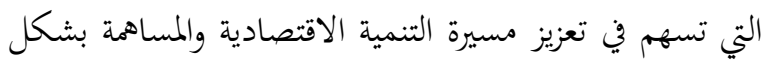
فعال في تدعيم وتنشيط عجلة الاقتصاد. وتتمثل عينة الدراسة بستة شركات صناعية والعاملة في محافظة دهوك/ منطقة

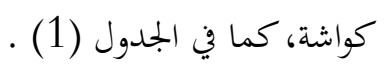

ب. الأداء الجزئي: هو قدرة النظام التحتي أو كل عنصر في المنظمة على تحقيق أهدافها بأدنى التكاليف الممكنة.

3/ المعيار الوظيفي

حسب هذا المعيار يقسم الأداء الى أداء الوظائف المعياء الوطيع الأساسية في المنظمة، وهي الإنتاج، المالية، التسويق، والأفراد

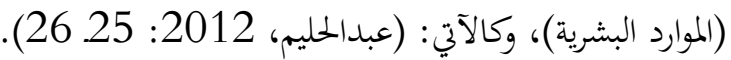
أ/ أداء وظيفة الإنتاج: يظهر الأداء في قدرة المنظمة على

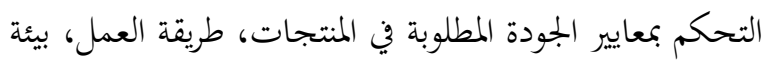

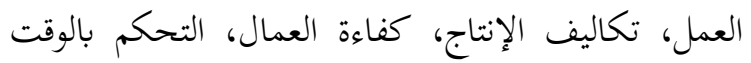
والإنتاج، المراقبة على الآلات، ومعدل التأخر في تلبية

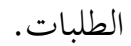
ب/ أداء الوظيفة المالية: ينعكس في قدرة المنظمة على تحقيق التوازن المالي، وبناء هيكل مالي فعال يحقق بلوغ أكبر عائد على الإستثمارات والوصول إلى أقصى مستويات المردودية الممكنة وغالباً ما تخضع هذهِ الوظيفة للتقييم وتحديد أدائها

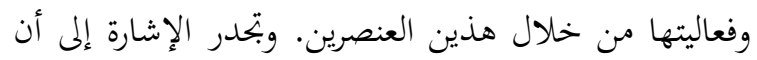
قدرة المسيرين على تحقيق هذا الهدف مقترن بالتحفيز الذي تهين تمنحهُ المنظمة سواء كان مادياً مقابل رفع المردودية أو معنوياً وذلك ببث روح المساهم بدل فكرة العامل الأجير. ج/ أداء الوظيفة التسويقية: يتحدد هذا الأداء من خلال قدرتهِ على تحسين المبيعات، رفع قيمة الحصة السوقية، تحقيق

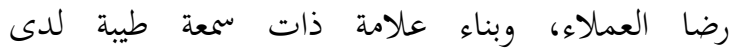
المستهلكين....الخ. وإن حقيقة أداء الوظيفة التسويقية تعتبر من التحديات الكبيرة في المنظمة إذ تطرح مشكلة قدرة تقييم

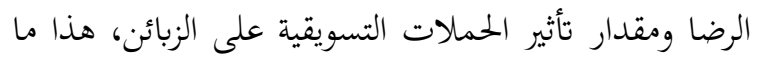
يفسر نسبة الدوران العالية للمستخدمين في هذهِ المصلحة

\begin{tabular}{|c|c|c|c|c|}
\hline منتجات الشركة & عدد العاملين & سنة التأسيس & اسم الشركة & ت \\
\hline أنابيب معدنية مختلفة الأنواع والاحجام & 60 & 2009 & معمل ماف لإنتاج الأنابيب المعدنية & 1 \\
\hline حديد مختلفة الأنواع والاحجام & 30 & 2010 & معمل قوج لإنتاج الحديد الفولاذ & 2 \\
\hline حديد مختلفة الأنواع والاحجام & 25 & 2011 & M.N.S كومبانيا & 3 \\
\hline الاسفلت & 20 & 2011 & معمل سيدو & 4 \\
\hline
\end{tabular}
وذلك راجع لصعوبة تقييم أدائهم مما يؤدي في كثير من

الجمدول (1): عرض موجز للشركات الصناعية المبحوثة 


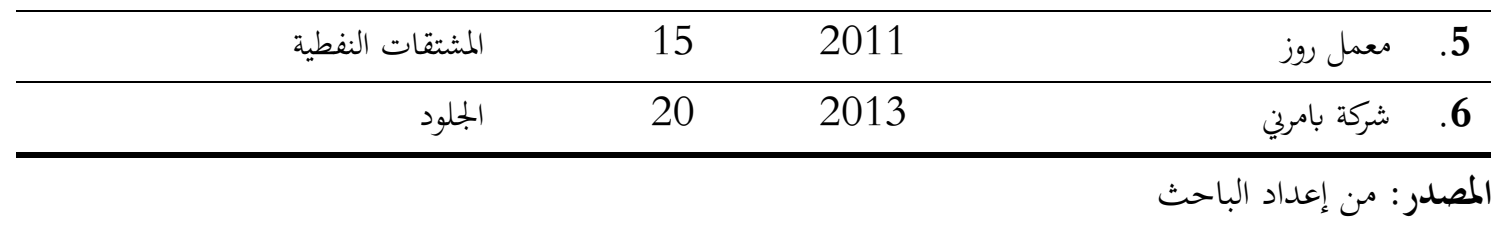

بيانات البحث، وتم إختبار فرضياتا بواسطة مجموعة من 2. 2. 2. وصف الافراد المبحوثين

جاءت محاولة الباحث لتناول موضوع مرتكزات إدارة الأساليب الإحصائية ومن خلال برنامج التحليل الإحصائي

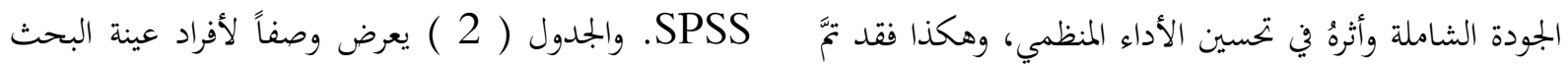

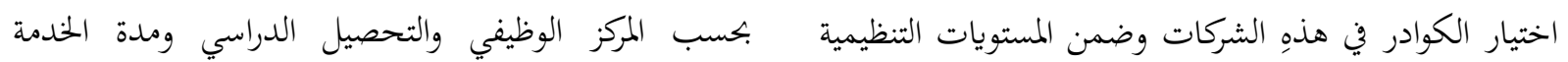
المختلفة، إذ وزعت 45 استمارة استبانة على الكادر الوظيفي ل للمبحوثين في الشركات المبحوثة.

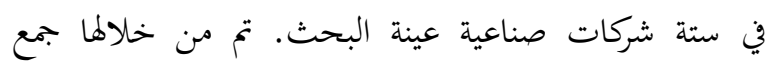

الجمدول (2): وصف الأفراد المبحوثين في الشركات المبحوثة

\begin{tabular}{|c|c|c|c|c|c|c|c|c|c|}
\hline \multicolumn{10}{|c|}{ المركز الوظيفي (المنصب) } \\
\hline \multicolumn{4}{|c|}{ الإدارة الوسطى والتنفيذية } & \multicolumn{6}{|c|}{ الإدارة العليا } \\
\hline \multicolumn{2}{|c|}{$\%$} & \multicolumn{2}{|r|}{ 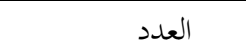 } & \multicolumn{3}{|c|}{$\%$} & \multicolumn{3}{|c|}{ العدد } \\
\hline \multicolumn{2}{|c|}{73.4} & \multicolumn{2}{|r|}{33} & \multicolumn{3}{|c|}{26.6} & \multicolumn{3}{|c|}{12} \\
\hline \multicolumn{10}{|c|}{ التحصيل الدراسي للأفراد المبحوثين } \\
\hline \multicolumn{2}{|c|}{ 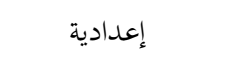 } & \multicolumn{2}{|c|}{ دبلوم فني } & \multicolumn{2}{|c|}{ بكالوريوس } & \multicolumn{2}{|c|}{ 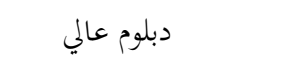 } & \multicolumn{2}{|c|}{ ماجستير } \\
\hline$\%$ & 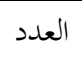 & $\%$ & العدد & $\%$ & العدد العد & $\%$ & العدد & $\%$ & العدد \\
\hline 26.6 & 12 & 24.5 & 11 & 26.6 & 12 & 17.8 & 8 & 4.5 & 2 \\
\hline \multicolumn{10}{|c|}{ مدة الحدمة في الشركة } \\
\hline \multicolumn{4}{|c|}{ أ أكثر } & \multicolumn{3}{|c|}{$3-4$} & \multicolumn{3}{|c|}{$2-1$} \\
\hline & & & الع & $\%$ & & العدد & $\%$ & & العدد \\
\hline \multicolumn{2}{|c|}{28.9} & \multicolumn{2}{|c|}{13} & \multicolumn{2}{|l|}{48.9} & 22 & \multicolumn{2}{|l|}{22.2} & 10 \\
\hline
\end{tabular}

يشير الجدول (3) إلى النسب المئوية والمتوسطات الحسابية والانحرافات المعيارية لمتغيرات البحث.

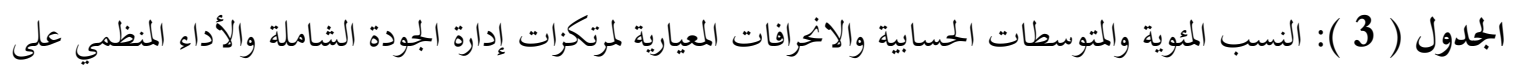
N = 45 مستوى الشركات الصناعية المبحوثة 


\begin{tabular}{|c|c|c|c|c|c|c|c|}
\hline \multirow[b]{2}{*}{ المالمعراف } & \multirow[b]{2}{*}{ الوسط الحسابي } & \multicolumn{5}{|c|}{ قياس الاستجابة } & \multirow{3}{*}{ المتغيرات } \\
\hline & & $\begin{array}{l}\text { لا أتفقة } \\
\text { بشدة } \\
\text { (1) }\end{array}$ & $\begin{array}{c}\text { لا أتفق }(2) \\
\text { (2) }\end{array}$ & $\begin{array}{l}\text { (3) } \\
\text { (3) }\end{array}$ & $\begin{array}{l}\text { أتفق } \\
(4)\end{array}$ & $\begin{array}{c}\text { أتفقة } \\
\text { (5) } \\
\text { (5) }\end{array}$ & \\
\hline & & $\%$ & $\%$ & $\%$ & $\%$ & $\%$ & \\
\hline 0.98 & 3.44 & 0.88 & 20.86 & 23.1 & 43.12 & 12 & التزام الادارة العليا \\
\hline 1.09 & 3.37 & 7.56 & 19.12 & 15.56 & 43.56 & 14.2 & التحسين المستمر \\
\hline 1.12 & 3.3 & 7.54 & 21.34 & 18.68 & 37.34 & 15.1 & رضا الزبائن \\
\hline 0.81 & 3.77 & 0.88 & 8.44 & 19.58 & 53.76 & 17.34 & التدريب ومشاركة العاملين \\
\hline 0.93 & 3.32 & 4 & 18.66 & 25.34 & 44.44 & 7.54 & التخطيط الاستراتيجي \\
\hline 1.06 & 3.37 & 8.05 & 17.5 & 19.71 & 37.79 & 16.95 & الأداء المنظمي \\
\hline
\end{tabular}

المصدر: من إعداد الباحث بالاعتماد على نتائج الحاسبة الالكترونية.

الشاملة. ويدعم ذلك قيمة الوسط الحسابي البالغة (3.77)،

وبانحراف معياري قيمتهُ (0.81).

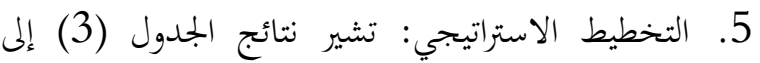
اتفاق (51.98 \% \% من المبحوثين على التزام الشركات المبحوثة بالتخطيط الاستراتيجي لمواجهة الظروف البيئية.

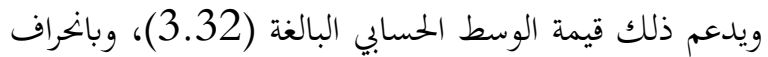

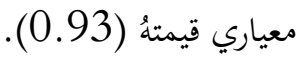

6. الأداء المنظمي: تشير نتائج الجدول (3) (3) إلى اتفاق (54.74 \%) من المبحوثين على امكانية زيادة كفاءة الأداء

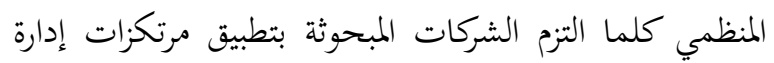
الجودة الشاملة. ويدعم ذلك قيمة الوسط الحسابي البالغة (3.37)، وبانحراف معياري قيمتهُ (1.06). ثالثاً/ اختبار نموذج البحث وفرضياتهِ همدف التعرف على طبيعة العلاقة والأثر بين مرتكزات

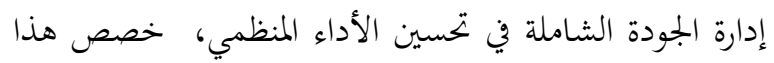
المحور للتحقق من مدى سريان نموذج البحث وكالآتي: 1. علاقات الإرتباط بين مرتكزات إدارة الجودة الشاملة وتحسين الأداء المنظمي يشير الجدول (4) نتائج علاقة الإرتباط بين متغيرات المدين

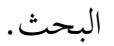

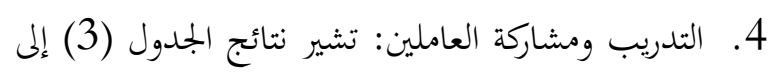

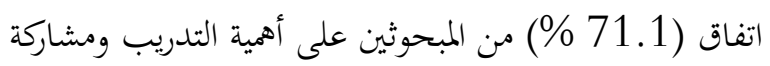
العاملين في الشركات المبحوثة للمساهمة في تحقيق الجودة الجدول ( 4 ) : نتائج علاقات الإرتباط بين مرتكزات إدارة الجودة الشاملة وتحسين الأداء المنظمي في الشركات المبحوثة

يشير الجدول (3) إلى النسب المئوية والمتوسطات الحسابية والانحرافات المعيارية لمتغيرات مرتكزات إدارة الجودة الشاملة والأداء المنظمي على مستوى الشركات المبحوثة، وفيما يأتي تحليل لهذهِ المتغيرات:

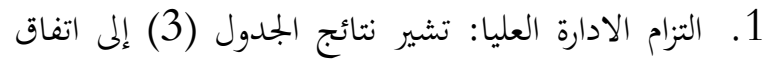
(55.12 \% من المبحوثين على التزام الادارة العليا بتطبيق

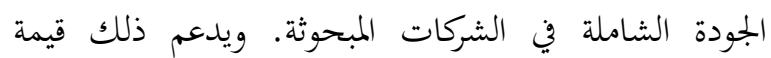
الوسط الحسابي البالغة (3.44) ، وبانحراف معياري قيمتهُ 2. التحسين المستمر: تشير نتائج الجدول (3) إلى اتفاق

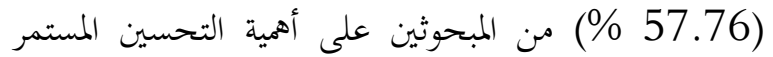
لكافة الأنشطة لتحقيق الجودة الشاملة في الشركات المبحوثة.

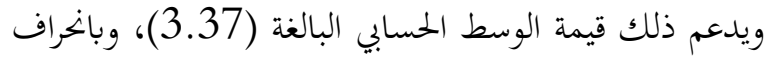
معياري قيمتهُ (1.09). 3. رضا الزبائن: تشير نتائج الجدول (3) (3) إلى اتفاق

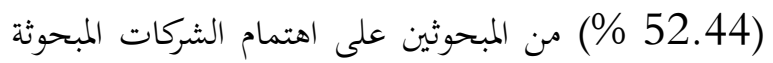
بزبائنها والوصول الى رضاهم من خلال تقديم منتجات ذات جودة عالية، ويدعم ذلك قيمة الوسط الحسابي البالغة (3.3)، وبانحراف معياري قيمتهُ (1.12). 


\begin{tabular}{|c|c|c|c|c|c|c|}
\hline \multirow[t]{2}{*}{ المؤشر الكلي } & \multicolumn{5}{|c|}{ مرتكزات إدارة الجودة الثاملة } & \multirow[b]{2}{*}{ / المتغير المعتمد / / / / / } \\
\hline & الاستراتيجيط & التاريب & الزبون & المستمر & الالادارة & \\
\hline $0.726^{*}$ & $0.580^{*}$ & $0.630 *$ & $0.690^{*}$ & $0.670^{*}$ & $0.785^{*}$ & تحسين الأداء المنظمي \\
\hline
\end{tabular}

$\mathrm{N}=45 * \mathrm{p} \leq 0.05$ "معنوية عند مستوى 0.05

المصدر: إعداد الباحث بالاعتماد على نتائج الحاسبة الالكترونية.

يبين الجدول (4) نتائج علاقة الإرتباط بين مرتكزات إدارة مرتكزات إدارة الجودة الشاملة في تحسين الأداء المنظمي في

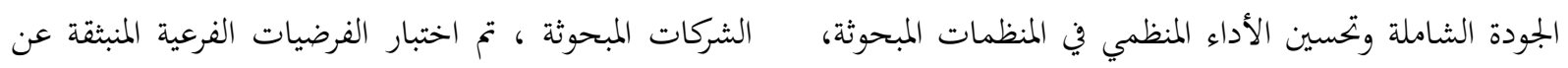

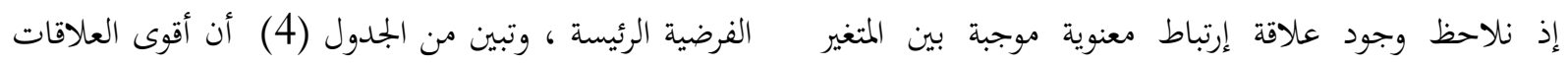

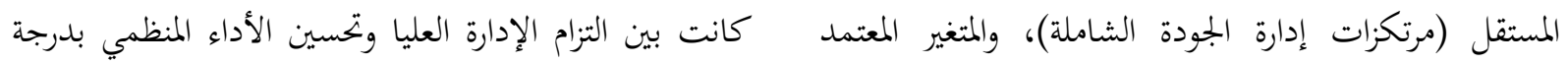

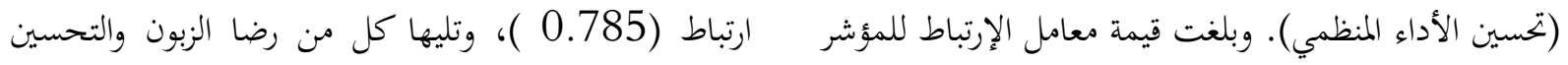
الكلي (0.726) وهي معنوية عند مستوى (0.05) وهو المستمر والتدريب ومشاركة العاملين والتخطيط الاستراتيجي

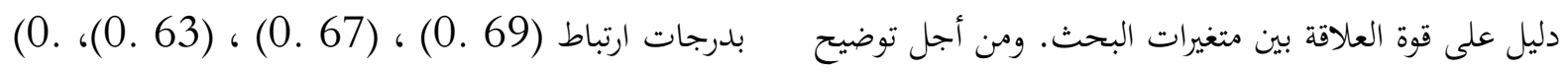

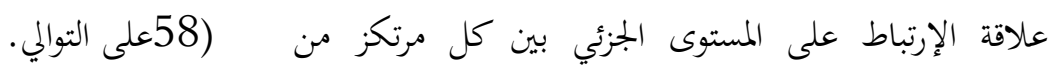
2. علاقة التاثير بين مرتكزات إدارة الجودة الشاملة وتحسين الأداء المنظمي على مستوى الشركات المتين المبحوثة. يعرض الجدول (5) نتائج علاقة التاثير بين مرتكزات ادارة الجودة الشاملة وتحسين الأداء المنظمي. الجحدول ( 5 ): تاثير مرتكزات إدارة الجودة الشاملة في تحسين الأداء المنظمي على مستوى الشركات المبحوثة

\begin{tabular}{|c|c|c|c|c|c|}
\hline \multicolumn{2}{|c|}{$\mathbf{F}$} & \multirow[b]{2}{*}{$\mathbf{R}^{2}$} & \multicolumn{2}{|c|}{ مرتكزات إدارة الجودة الشاملة } & \\
\hline الجدولية & الخسوبة & & $\mathbf{B}_{1}$ & $\mathbf{B}_{0}$ & \\
\hline 4 & 78.75 & 0.52 & $\begin{array}{l}0.731 \\
(8.89)\end{array}$ & 0.922 & تحسن الأداء \\
\hline
\end{tabular}

$\mathrm{N}=45$ *P $<0.05$

(8.89) يشير إلى قيمة الخسوبة

df $(1,43)$

تشير نتائج الانحدار على مستوى هذهِ الشركات إلى وجود

تأثير معنوي موجب بين مرتكزات ادارة الجودة الشاملة في

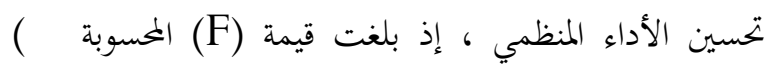

( 78.75 وهي أعلى من قيمتها الجدولية والبالغة (5). وبلغ الغئل

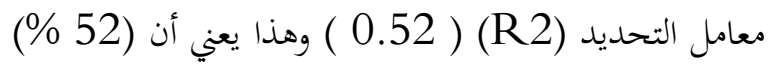
من الاختلافات المفسرة في تحسين الأداء المنظمي تفسرها

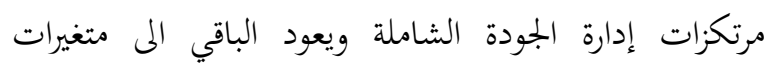

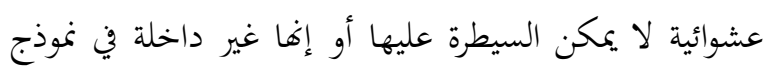

المصدر: إعداد الباحث بالاعتماد على نتائج الحاسبة الالكترونية.

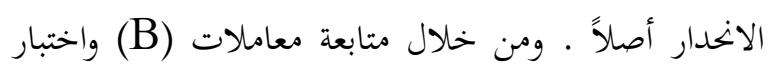

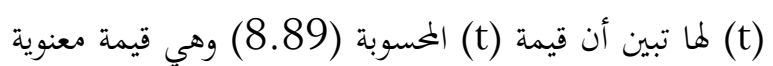

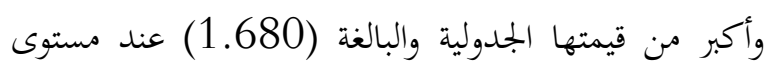
معنوي (0.05). وبهدف توضيح علاقة الأثر بين كل مرتكز من مرتكزات

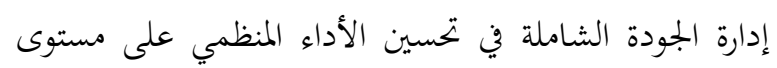

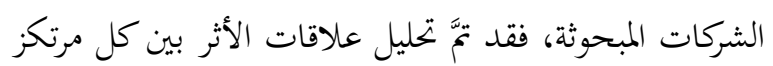

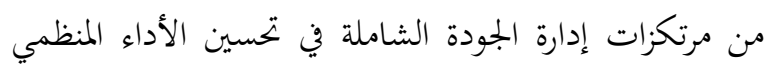


على مستوى الشركات المبحوثة بصورة منفردة كما في الجدول

الجحدول ( 6 ) ): تاثير كل مرتكز من مرتكزات إدارة الجودة الشاملة في تحسين الأداء المنظمي على مستوى الشركات المبحوثة

\begin{tabular}{|c|c|c|c|c|c|c|c|c|c|}
\hline \multicolumn{2}{|c|}{$\mathbf{F}$} & \multirow{2}{*}{$\mathbf{R}^{2}$} & الاستراتيجي & والتشاريب & الزبون & المستمسين & الالتزام العليا & \multirow{2}{*}{ Bo } & الممتثيرات \\
\hline الجحدولية & الخحسوبة & & B5 & B4 & B3 & B2 & B1 & & \\
\hline 2.3 & 3.8 & 0.8 & $\begin{array}{c}0.27 \\
*(5.85)\end{array}$ & $\begin{array}{c}0.26 \\
*(6.25)\end{array}$ & $\begin{array}{c}0.24 \\
*(7.65)\end{array}$ & $\begin{array}{l}0.265 \\
(6.4)^{*}\end{array}$ & $\begin{array}{c}0.25 \\
*(7.15)\end{array}$ & 1.7 & تحسين الأداء \\
\hline
\end{tabular}

$\mathrm{N}=45 * \mathrm{P}<0.05$

t

df $(6,38)$

المصدر: إعداد الباحث بالاعتماد على نتائج الحاسبة الالكترونية

تاسيساً على ما تقدم تقبل الفرضية التي تنص على "

وجود علاقة معنوية موجبة بين مرتكزات إدارة الجودة

الشاملة وبين الأداء المنظمي في الشركات المبحوثة".

الاستنتاجات والمقترحات

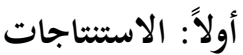

1. أظهرت النتائج علاقة ايجابية ومعنوية بين مرتكزات إدارة

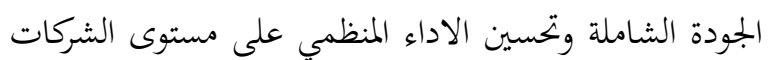
المبحوثة، مما يعني إستجابة أفراد العينة لمرتكزات إدارة الجودة المهاء

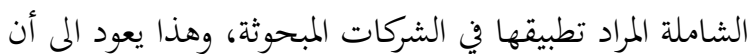

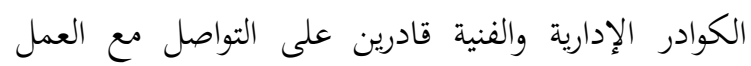
ومواجهة التحديات التي تواجة أدائهم.

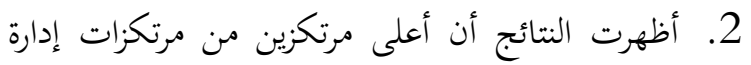
الجودة الشاملة من حيث المعنوية كان رضا الزبون في المرتبة

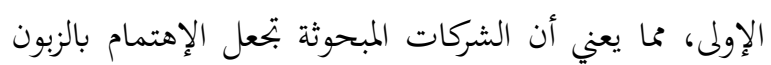

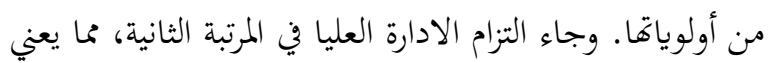

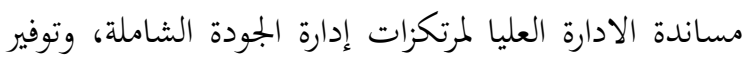

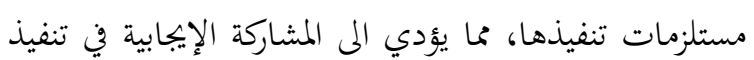

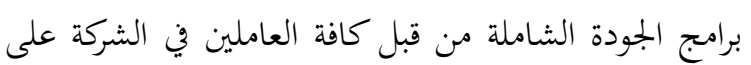

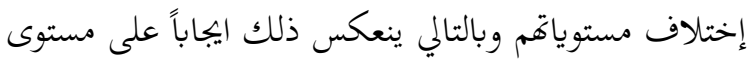

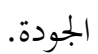

تشير نتائج الانحدار على مستوى الشركات المبحوثة إلى

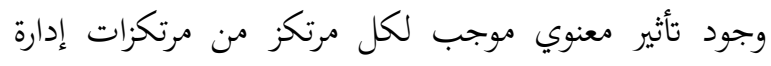

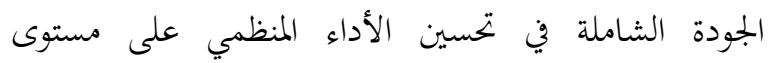

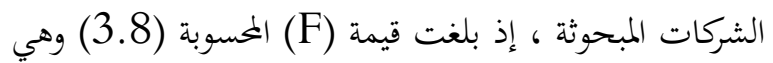

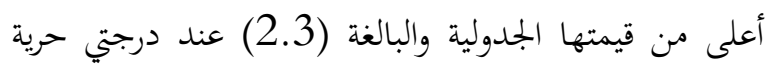

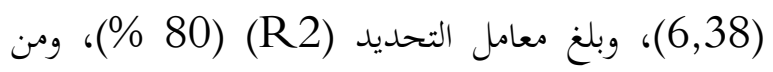

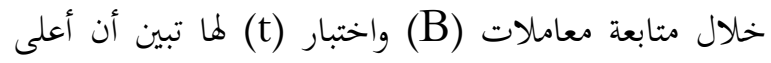
مرتكز من حيث المعنوية كان رضا الزبون اذ بلغت قيمة (t) المحسوبة (7.65) وهي أعلى من قيمتها الجدولية والبالغة (1.680) عند مستوى معنوي (0.05). وجاء التزام الادارة

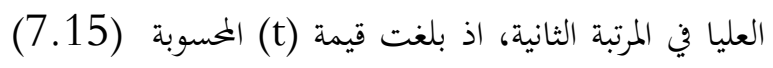
وهي أعلى من قيمتها الجدولية والبالغة ( 1.680 ) عند مستوى معنوي (0.05)). وجاء التحسين المستمر في المرتبة

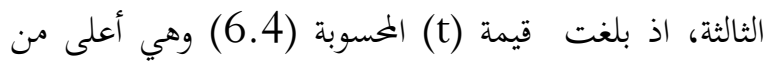

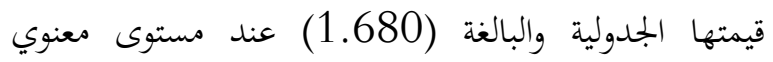

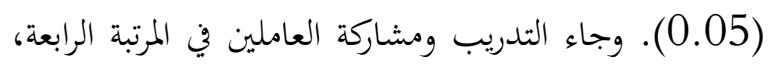
اذ بلغت قيمة (t) المحسوبة (6.25) وهي أعلى من قيمتها الجدولية والبالغة (1.680) عند مستوى معنوي (0.05). وجاء التخطيط الاستراتيجي في المرتبة الخامسة، اذ بلغت قيمة

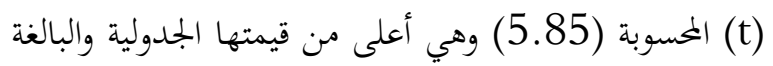

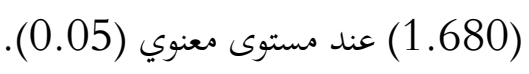


2. التوسع في تطبيق برنامج إدارة الجودة الشاملة في الشركات الصناعية، والإطلاع على ما حققتهُ الشركات العالمية من نجاحات متميزة عبر تطبيقها لبرامج إدارة الجودة الشاملة. 3. ضرورة التعاون بين الشركات المبحوثة والجامعات والمعاهد في مجال إقامة الدورات التدريبية لترسيخ أسس الجودة الشاملة لدى الأفراد العاملين لمواكبة التقدم التقاني في الصناعة. 4. ضرورة خلق بيئة تدعم وتحافظ على التحسين والتطوير المستمرين للصناعة. 5. يدعو الباحث إدارة الشركات المبحوثة إلى الاهتمام المتزايد بأبعاد الأداء المنظمي واستخدام مؤشرات مناسبة لهذهِ

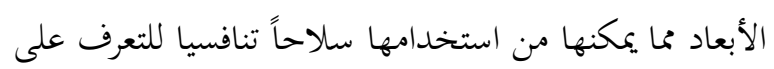
واقع الشركات ولمواكبة الشركات العالمية خصوصا وإفا تعمل في بيئة تتسم بالديناميكية العالية.

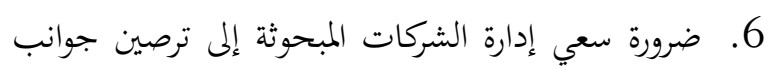
القوة لديها فيما يتعلق بإدارة الجودة الشاملة والإطلاع على أحدث التطورات التقنية في مجال تطبيقها، والانفتاح على الأسواق الإقليمية والسعي لتبادل الخبرات، والبحث المشترك عن فرص جديدة لتحسين الأداء المنظمي، وايجاد أسواق مشتركة لتنمية الاستثمارات.

قائمة المصادر اولاً/ المصادر العربية

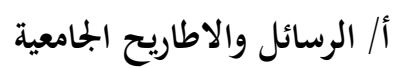
1. أم العز، حمودي، 2012، دور تطوير المنتجات في تحسين أداء المؤسسات الصغيرة والمتوسطة، دراسة حالة مؤسسة وحدة تحويل البلاستيك بالجنوب - ورقلة ، رسالة ماجستير غير منشورة، جامعة قاصدي مرباح ورقلة، كلية العلوم الاقتصادية والتجارية وعلوم التسيير، الجزائر، httpbu.univ-ouargla.dz 2. بوغابة، كوثر، 2012، دور الموازنة التقديرية في تحسين أداء المؤسسة الإقتصادية ، رسالة ماجستير غير منشورة، جامعة قاصدي مرباح ورقلة، كلية العلوم الاقتصادية والتجارية وعلوم التسيير، الجزائر، httpbu.univ-ouargla.dz. 3. تيمجغدين، عمر، 2013، دور إستراتيجية التنويع في تحسين أداء

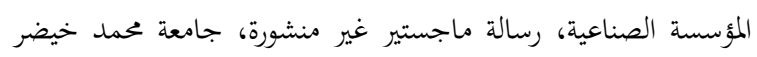
بسكرة، كلية العلوم الاقتصادية والتجارية وعلوم التسيير، الجزائر، .httpuniv-biskra.dz
3. أظهرت النتائج أن أقل مرتكزين من حيث المعنوية كان التدريب ومشاركة العاملين، والتخطيط الاستراتيجي، مما يعني ضعف التدريب وعدم المشاركة الإيجابية للعمال في برامج تحسين الجودة، أما ضعف التخطيط الاستراتيجي يعني عدم استشراف متغيرات المستقبل وتحليل بيئة المنظمة داخلياً وخارجياً، وبالتالي عدم الإستفادة من الفرص المتاحة ومواجهة التحديات القائمة والمتوقعة. 4. أظهرت نتائج تحليل وصف وتشخيص متغيرات البحث أن أغلب إجابات الأفراد المبحوثين تركز على الموافقة والموافقة بشدة على جميع مرتكزات إدارة الجودة الشاملة في الشركات المبحوثة، محا يدل على اهتمام الشركات المبحوثة بتطبيق مرتكزات إدارة الجودة الشاملة. 5. أظهرت نتائج تحليل وصف وتشخيص متغيرات البحث إلى أن مرتكز التدريب ومشاركة العاملين حصل على أعلى نسبة اتفاق للمبحوثين وبنسبة (71.1 $71 \%$ \%)، وبوسط حسابي (3.77)، وبانحراف معياري (0.81). مما يدل على أن الشركات المبحوثة تجعل هذا المرتكز من أولويات أهتمامها. بينما حصل مرتكز التخطيط الاستراتيجي على أقل نسبة اتفاق للمبحوثين مقدارهُ (51.98 \% \%)، وبوسط حسابي (3.32)، وبانحراف معياري (0.93). ويدل ذلك على (0لى ضعف اهتمام الشركات المبحوثة بهذا المرتكز مقارنةً بباقي

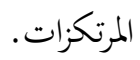
ثانياً/ المقترحات آثرات استكمالاً لمتطلبات المنهجية وتأسيساً على ما توصلت إليه الباحث من نتائج وما بنيت من استنتاجات وجد الباحث انهُ من المفيد تقديم المقترحات الآتية : 1. ضرورة التزام الإدارة العليا في الشركات الصناعية بتطبيق مرتكزات الجودة الشاملة في بيئة عملها لتحقيق مزايا عديدة من أهمها التحسين في الأداء المنظمي محا يعزز من قدرة هذهِ الشركات في إمكانية تحقيق ميزة تنافسية من خلال تقديم منتجات وخدمات بجودة ملائمة لحاجات ورغبات الزبائن. 
5. عبد الحميد، برحومة ومراد، شريف ،2008، الجودة الشاملة ومواصفات الايزو كأداة لتفعيل تنافسية المؤسسة الاقتصادية، مجلة أبحاث إدارية واقتصادية، العدد الثالث، كلية العلوم الاقتصادية وعلوم التسيير والعلوم التجارية، جامعة محمد بو ضياف المسيلة، الجزائر. 6. اللوزي، موسى، 2004، دور المدير العربي في الإبداع والتميز،

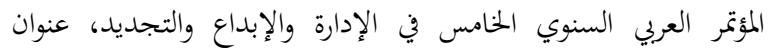

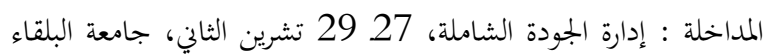
التطبيقية، الاردن. - مان. 7. مناصرية، رشيد، 2012، أهمية الكفاءات البشرية في تطبيق إدارة الجودة الشاملة بالمؤسسة، دراسة حالة مؤسسة سوناطراك، حاسي مسعود، الجزائر، مجلة الباحث، عدد 11، كلية العوسله، دراسله العلوم الاقتصادية والتجارية وعلوم التسيير، جامعة قاصدي مرباح ورقلة، الجزائر. ج/ الكتب 1. عقيلي، عمر وصفي ، 2001 ، إدارة الجودة الشاملة ، ط1 ، أ

$$
\begin{aligned}
& \text { مطابع حلب للنشر والتوزيع، سوريا. } \\
& \text { ثانياً/ المصادر الاجنبية }
\end{aligned}
$$

1. Allen, Verna, 2003: The Knowledge and Evaluation, MA Boston: ButterworthHeinemann.

2. Barker J.Kathreine and Cagwin Douglas, (2000), “New Evidance Rrlating TQM To Financial Performance": An Empirical Study of Management Firms. www.quality.foundation.co.uk/pdf .

3. Besterfield, DaleH. Besterfield-Michna, Carol; Besterfield, Glent H., BesterfieldSacre, Mary (2005). Total Quality Management ،3rd.ed, Pearson education (Singapore) pte.Ltd., Indian Branch.

4. Cameron, Kim and Quinn، Robert، ، 2011 Diagnosing and Changing Organizational Culture: Based on the Competing Values Framework, John Wiley and Sons.

5. Chong, Vincent k.\&Rundus, Michael J: Total Quality Management Market Competition and Organizational
4. السامرائي، برهان الدين حسين، 2012، دور القيادة في تطبيق

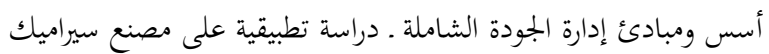
راس الخيمة ، رسالة ماجستير غير منشورة، الأكاديمية العربية البريطانية

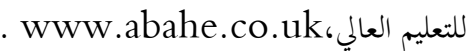
5. سليماني، محمد، 2007، الابتكار التسويقي وأثره على تحسين أداء المؤسسة، رسالة ماجستير غير منشورة، جامعة مسيلة، الجزائر، .www.pdffactory.com 6. عبد الحليم، مزغيش ، 2012، تحسين أداء المؤسسة في ظل إدارة الجودة الشاملة، رسالة ماجستير غير منشورة، جامعة الجزائر كلية العلوم الاقتصادية وعلوم التسيير، الجزائر. 7. ملوك، منصف، 2010، أثر إشهاد الجودة على أداء المؤسسات الجزائرية حالة المواصفة (2000) ISO 9001 . دراسة إحصائية بالمؤسسة الوطنية لأجهزة القياس والمراقبة، رسالة ماجستير، جامعة فرحات عباس ـ سطيف، كلية العلوم الاقتصادية وعلوم التسيير، الجزائر ، .httpwww.univ-setif.dz 8. النحوي، محمد محمود عبداللة، 2013، أهمية التكامل بين ادارة الجودة الشاملة وتقنيات ادارة التكلفة في تحسين الأداء في الشركات الصناعية المساهمة العامة الأردنية، رسالة ماجستير غير منشورة، جامعة

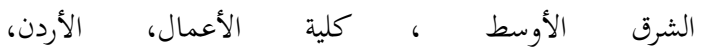
.httpwww.meu.edu.

1. شاهين، علي محمد،" إدارة الجودة الشاملة و أنظمتها في نجاح

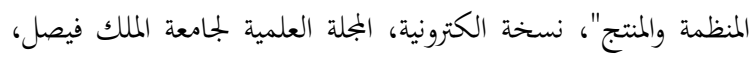
المملكة العربية السعودية، المجلد ه ، العدد الأول، ع . . ب. 2. الشماع، سعد والطويل، أكرم، ورشيد، حكمت، والشهواني، نوفل ، 2001 ، دراسة موقفية لإمكانية تطبيق إدارة الجودة الشاملة في قطاع بكثي، مجلة تنمية الرافدين ، جامعة الموصل ، العدد (66) ، المجلد .23/4 3. الصفار، أحمد عبد إسماعيل وعبد اللطيف، ماجدة، 2008، أثر تطبيق فلسفة ادارة الجودة الشاملة وفق منظور الزبون الداخلي والخارجي على الاداء التشغيلي للمنظمات، مجلة الادارة والاقتصاد ، العدد الثالث والسبعون، الاردن. 4. الطويل، اكرم وسلطان، حكمت، ( 2001 ) ) ، امكانية تطبيق ادارة الجودة الشاملة في الصناعات العراقية، دراسة استطلاعية لاراء المدراء في عينة من الشركات الصناعية الخاصة/ نينوى، مجلة بجوث

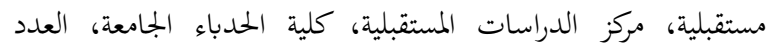

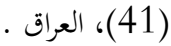


10. Slack, Nigel and Chambers, Stuart, and Johnston, Robert, 2004, Operations management, 4th ed., Prentice - Hall, New York.

11. Steven.P. Browan and Wynne W. Chin, (2004) , "Satisfying and Retaining Customers through Independent Service Representatives" . Journal Decision science, sammer, No.3, Vol. 35, printed in the U.S.A. www.blackwell.com/pdf.

12. Thomas j. Douglas and Lawrence D. Fredendall ., (2004), "Evaluating the Deming Management Model of Total Quality in Service" . Journal Decision science,No.3,Vol.35, printed in the U.S.A.www.blackwell.com.
Performance", The British accounting Review36.2004.

6. Dimitriades, A. 2001، Empowerment in Total Quality Management : Academy of Management, McGraw - Hill, New York.

7. Evans,Jams R.,(1997), "Production Operation Management Quality Performance and value ",(5th ed), West publishing $\mathrm{CO}$,NewYork .

8. Hezir \& Render,Barry.,(2001), “ Operation Management " U.S.A., preintice-Hill,New Jersey.

9. Robbins, Stephen p \& Coulter, Mary,(2005). Management, 8th.ed , Pearson Education, Inc., Upper saddle River, New Jersey, 07458.

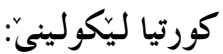

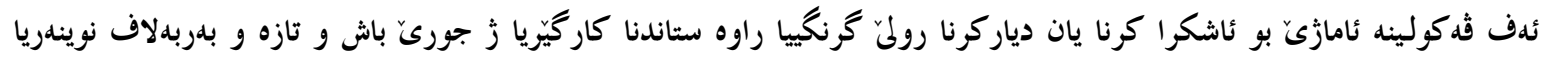

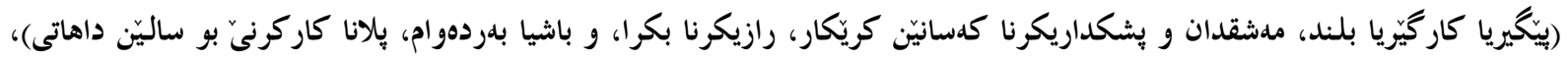

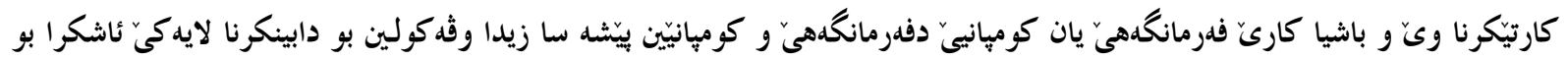

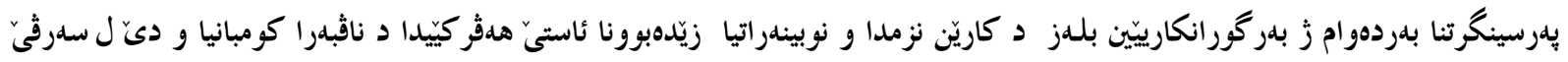

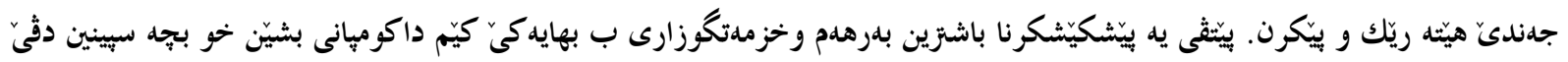

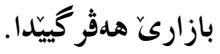

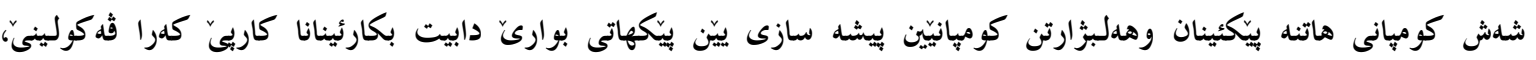

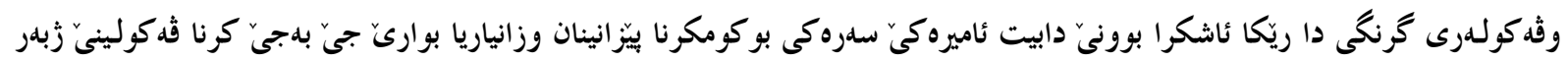

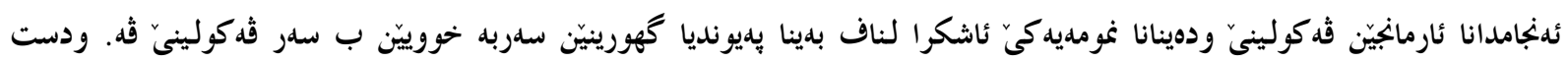

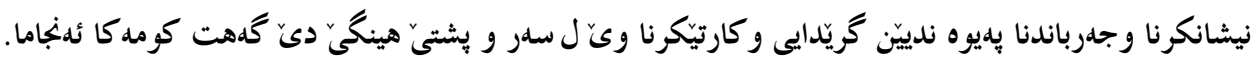

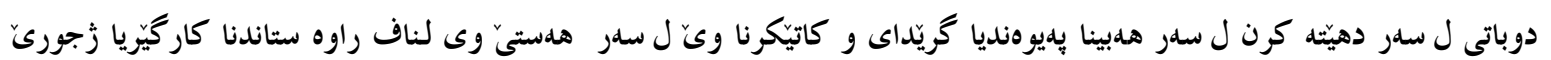

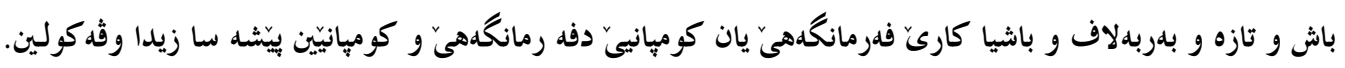

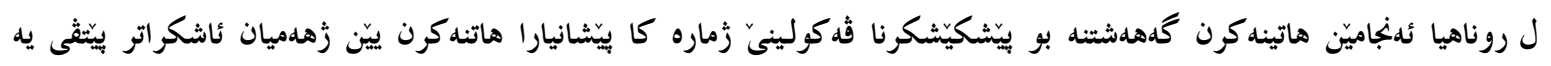

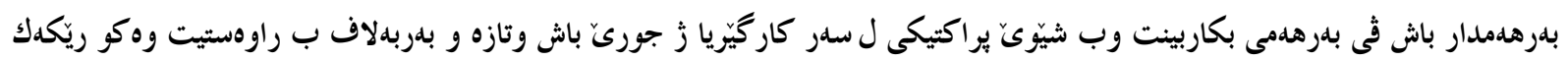

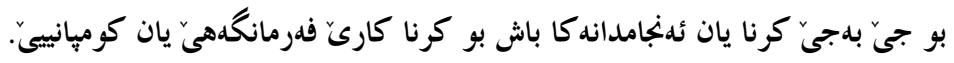

\section{Abstract}

The research inicatet to declare the most pillar of Total Quality Management which represented in (obligation of Top Management, training and participation of individuals workers, customer 
satisfaction, continuous improvement, Strategically planning), and their effects in improvement of organizationl performance in industrial organizations to provide a clear way in conformance the continuous difficulties because of speed changing in the world of businesses which is represented in the increasing of a sharp competition between the companies and the consequent need to provide the best products and service and the lowest prices so that the company can prove itself in this competitive market.

A group of six industrial companies have been chosen to be the field in which the practical part would be done. The researcher has depended on the questionnaire as a main tool to collect the data and the information in the practical part of the study, to achieve the aims of the study and to test the hypotheses of the study, a hypothetical model has been designed to show the nature of the relationship between the variables in the study. Depending on the description and the specification of the variables in this study and testing the correlation relationships and the impact, a set of conclusions have been reached. The most prominent conclusions are there is a positive significant correlation relationship and significant impact relationship among the Total Quality Management Fundamentals and the improvement of organizations performance in all the examined companies.

Depending on the conclusions that have been reached by the researcher, the study presents a number of suggestions, notably the need to adopt the Total Quality Management Fundamentals to enhance the achievement of the performance of enterprise of companies surveyed.

Keywords: Total Quality Management Fundamentals, performance of enterprise, Institutional Performance, Performance Improvement.

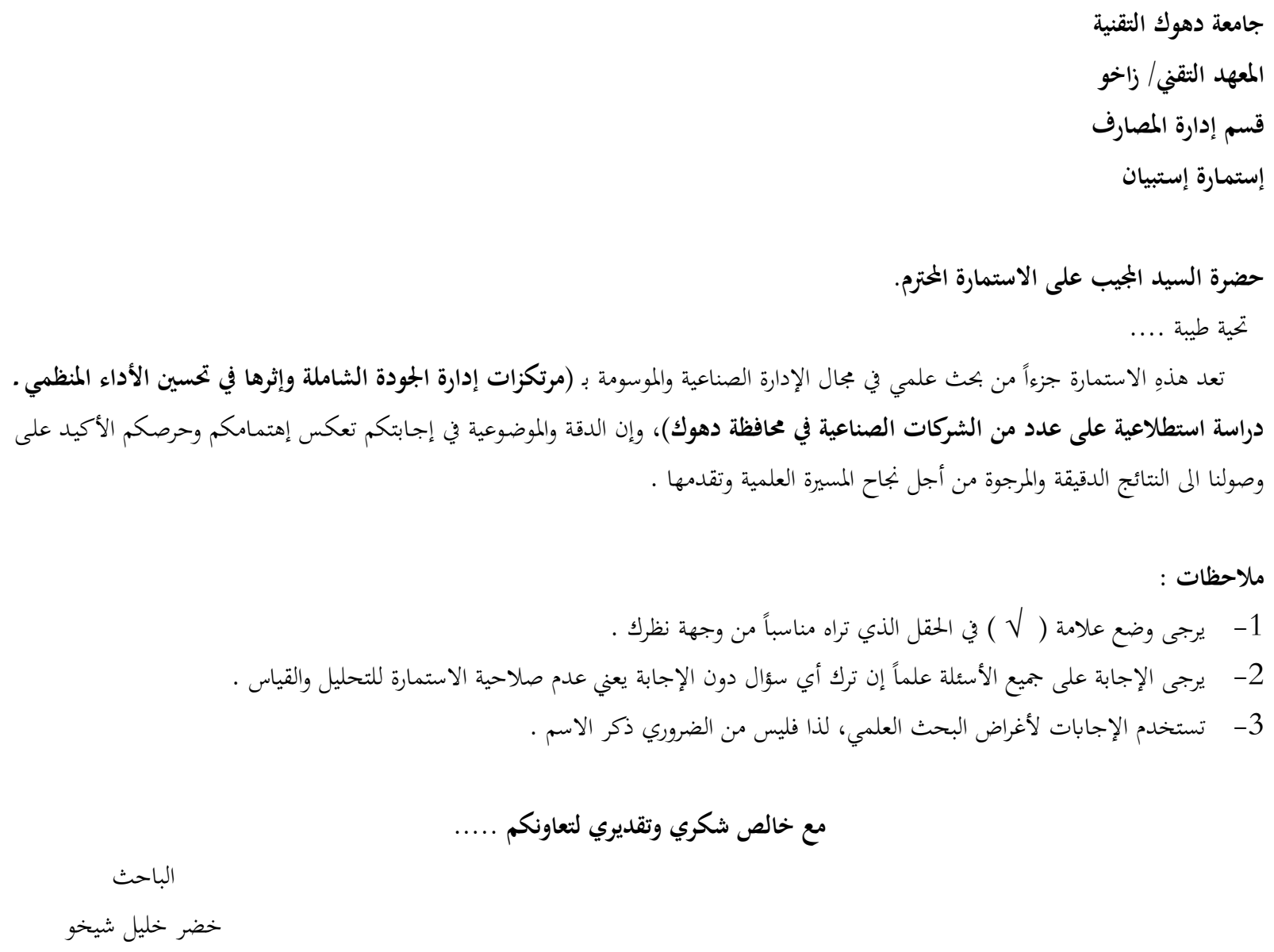


مدرس مساعد

2015/7/26

$$
\begin{aligned}
& \text { أولاً/ معلومات عامة }
\end{aligned}
$$

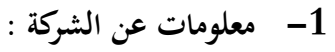

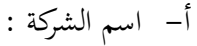

$$
\begin{aligned}
& \text { ب- تاريخ تأسيس الشركة: }
\end{aligned}
$$

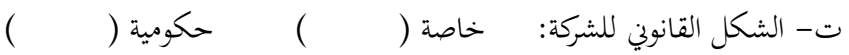

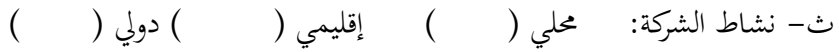

$$
\begin{aligned}
& \text { ج- المنتجات التي تنتجها الشركة: } \\
& \text { ح- عدد العاملين في الشركة: } \\
& \text { 2- - معلومات تتعلق بالجيب على الاستمارة: }
\end{aligned}
$$

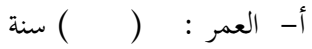

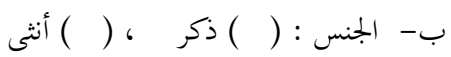

$$
\begin{aligned}
& \text { ت - التحصيل الدراسي : ( ) ) دكتوراه ، ( ) ماجستير ، ( ) ) دبلوم عالي }
\end{aligned}
$$

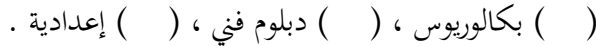

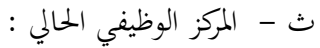

$$
\begin{aligned}
& \text { ج - مدة الخدمة بالمركز الوظيفي الحالي : }
\end{aligned}
$$

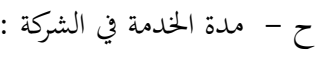

ثانياً/ مرتكزات إدارة الجحودة الشاملة: ويتضمن مجموعة من العناصر والمبادئ الواجب الالتزام بها لتحقيق النجاح في تطبيق مفهوم الجودة الشاملة، وتتمثل أهم هذهِ العناصر بـ : التزام الإدارة العليا، والتحسين المستمر، ورضا الزبائن، ومشاركة العاملين، والتخطيط الاستراتيجي. وتمدف هذا ولتها الأسلوب الإداري الى تحقيق تحسين الأداء الإداري للشركة، وتحقيق رضا الزبائن عن منتجاتما.

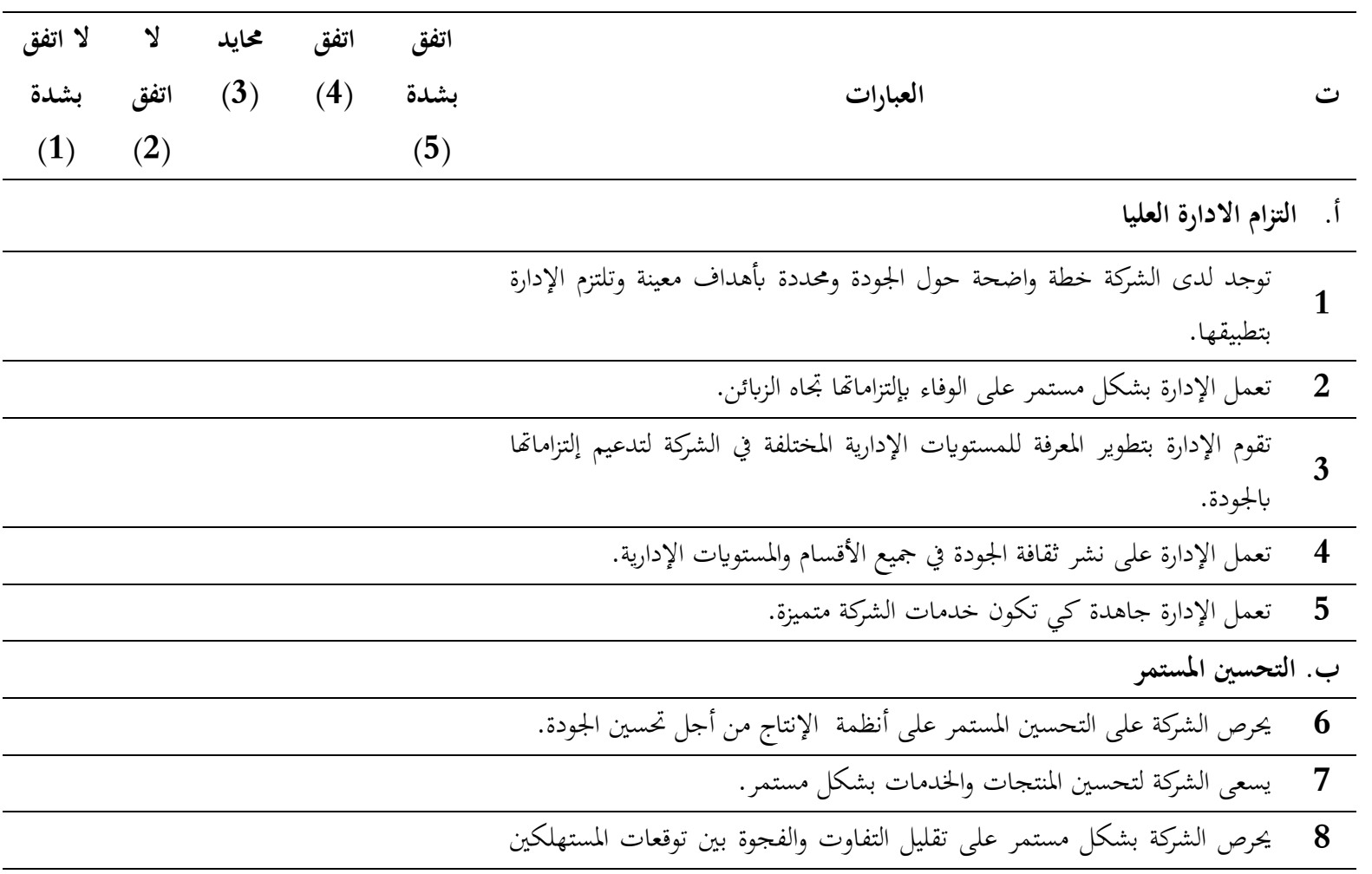




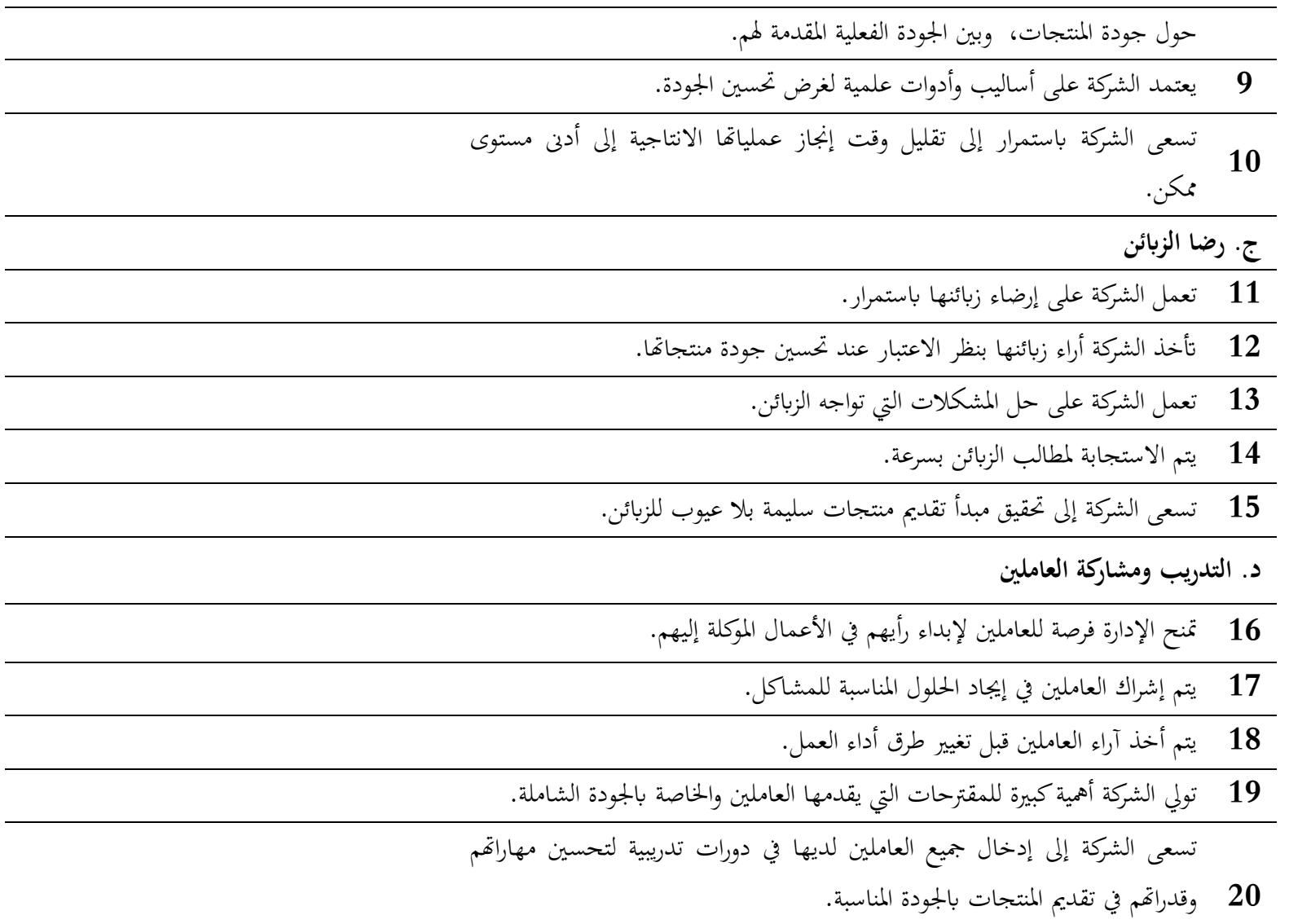

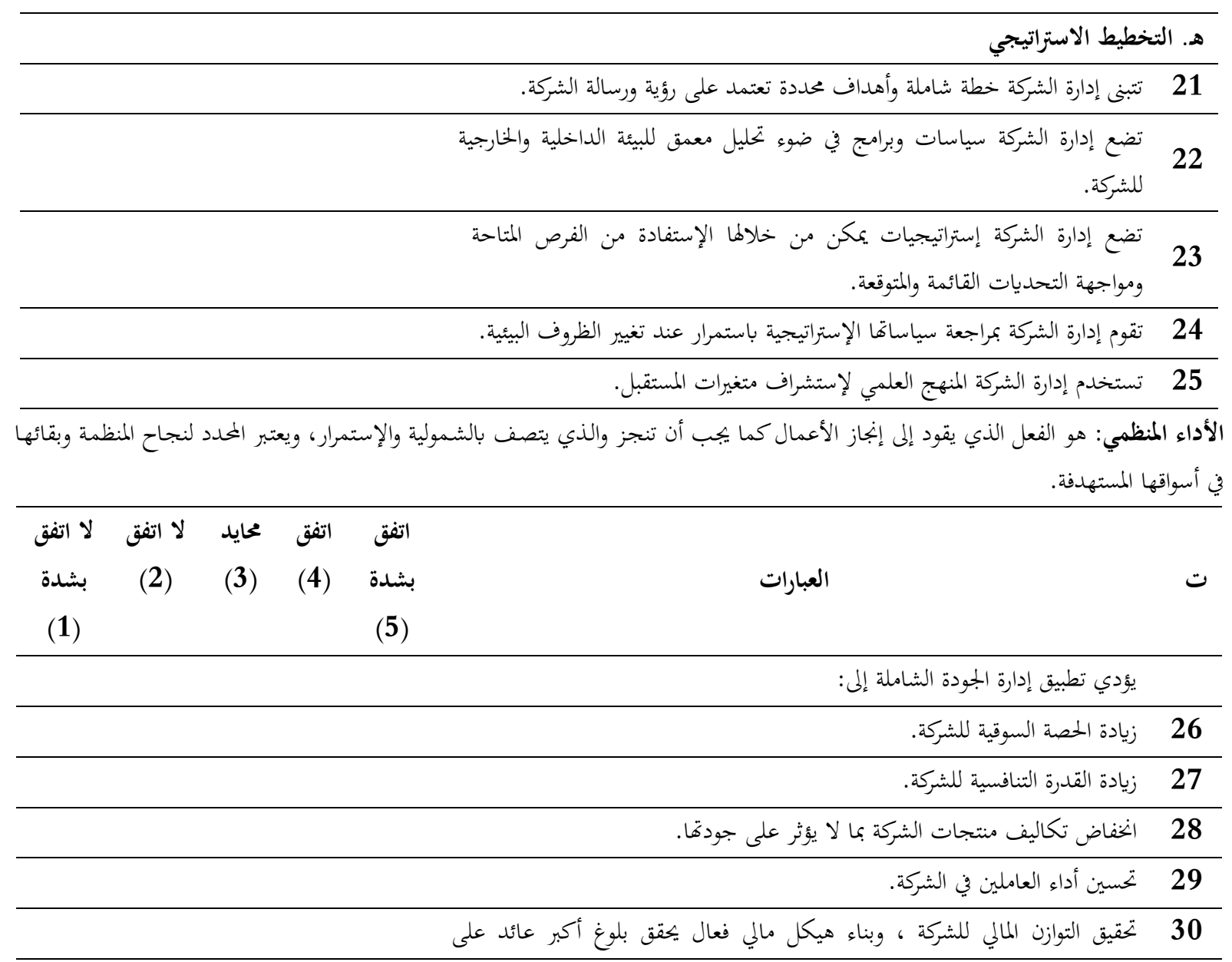




\begin{aligned} & \hline 31 \\ & \hline 32 \\ & \hline الإستثمارات 31 \\ & \hline 33 \\ & \hline\end{aligned}

